\title{
4
}

\section{Induction Motor Vector and Direct Torque Control Improvement during the Flux Weakening Phase}

\author{
Kasmieh Tarek \\ Higher Institute for Applied Sciences and Technology \\ Syria
}

\section{Introduction}

Some industrial applications, such as spindle, traction, and electric vehicles, need a high speed for the fixed rating power, Fig. 1. To achieve this goal a suitable control method based on the flux weakening is usually applied. This gives an economic solution for the power converter and the motor (Grotstollen, H. \& Wiesing, J, 1995).

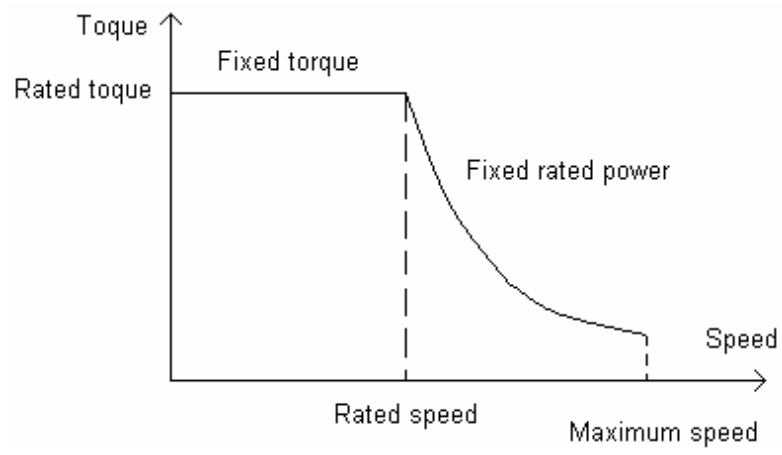

Fig. 1. Motor torque according to speed range

For the induction motor, its magnetic state changes during the flux weakening phase. It goes from the saturation to the linear region, since the rating magnetic point is at the knee of the magnetizing curve of the iron. Therefore, the change of the magnetic state of the motor should be taken into account in the control law.

Field Oriented Control (FOC) and Direct Torque Control (DTC) are based on a linear twophase model of the induction motor (Vas, P. \& Alakula, M. 1990). This model considers that the magnetic state of the motor is fixed, and all control parameters are calculated according to this state. When decreasing the flux level, the motor inductances increase. The change of real inductances values of the motor influences the desired current and speed dynamics.

In this chapter, the linear two-phase model of the induction motor is re-examined, and a new non linear two-phase model of the induction motor is developed. This model takes into account the variation of the saturation level (Kasmieh, T. \& Lefevre, Y, 1998). The calculation 
of this model needs the motor inductances values at each calculation step. The inductances curves, as functions of the magnetic state of the motor, can be obtained using a finite elements calculation program.

Unlike many models developed for the induction motor that take into account the variation of the saturation level (Vas, P, 1981), the model presented in this chapter does not introduce the inductances time derivatives. This leads to an easy computation algorithm, using iteration method at each calculation step. The derived model is validated by comparing its dynamic behavior to the dynamic behavior of a finite elements model.

Based on the new model, a complete sensitivity study of the classical FOC and DTC techniques is presented. The FOC is highly dependent on the motor parameters. During the flux weakening phase, the inductances values increase. This influences the dynamic behavior fixed by the controllers, which is calculated for the rating inductances values. To overcome this problem an adaptive FOC is introduced. At each sampling period, the magnetic state of the motor is calculated by iteration, and then the controllers are tuned to this new magnetic state. Concerning the DTC, this control law is less sensitive to the variation of the saturation level (Kasmieh, T, 2008). The DTC is based on applying the good voltage stator vector in order to achieve the desired stator fluxes and torque variations. The main problem of the DTC lies in is the accuracy of the stator fluxes calculation at each sampling period. Usually, this calculation is easily done by using the stator electric equation. The performance of this estimator is highly dependent on the value of the stator winding resistor, which varies with the motor temperature. A more complicated flux estimator can be derived from the rotor electric equation (Kasmieh, T, 2008). This estimator is less sensitive to the variation of the rotor resistor, but more sensitive to the variation of the saturation level. To overcome this problem, an adaptive flux estimator is presented in this chapter. The estimator parameters are tuned according to the saturation level of the motor. This new estimation method increases the computation time of the DTC, but it remains smaller than the computation time of the FOC.

\section{Magnetic state study of the induction motor using finite elements calculation program}

The goal is to determine the main variable that influences the magnetic state of the induction motor, and to establish new flux-current relationships in the two-phase reference that take into account the influence of the magnetic saturation level variation. The study is done for a two pole pairs $(\mathrm{p}=2) 45(\mathrm{KW})$ induction motor using a finite elements calculation program.

Fig. 2 shows the cross section of the studied $45(\mathrm{KW})$ induction motor. The motor has two cages of 40 bars each.

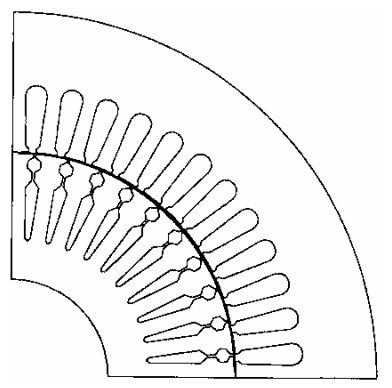

Fig. 2. Cross section of the studied $45(\mathrm{KW})$ induction motor 
The induction motor is modeled as a magnetic circuit of 3 stator phases and $\mathrm{m}$ rotor phases, $(\mathrm{m}=10$ in the case of the $45(\mathrm{KW})$ induction motor), Fig. 3.

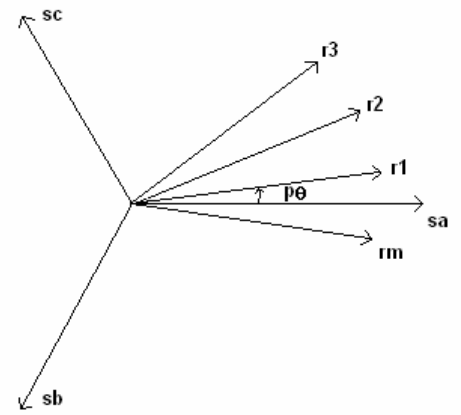

Fig. 3 Axes of multi-phase model of an induction motor

The flux-current relationships can be written as follows:

$$
[\phi]_{\mathrm{m}+3}=\left[\begin{array}{cc}
{\left[\mathrm{L}_{\mathrm{ss}}\right]_{3,3}} & {\left[\mathrm{M}_{\mathrm{sr}}(\theta)\right]_{3, \mathrm{~m}}} \\
{\left[\mathrm{M}_{\mathrm{rs}}(\theta)\right]_{\mathrm{m}, 3}} & {\left[\mathrm{~L}_{\mathrm{rr}}\right]_{\mathrm{m}, \mathrm{m}}}
\end{array}\right] \cdot[\mathrm{I}]_{\mathrm{m}+3}
$$

The elements of the vector $[\phi]_{\mathrm{m}+3}$ are the stator and rotor fluxes, the elements of the vector $[\mathrm{I}]_{\mathrm{m}+3}$ are the stator and rotor currents, $\left[\mathrm{L}_{\mathrm{ss}}\right]_{3,3}$ is the stator inductance matrix, $\left[\mathrm{L}_{\mathrm{rr}}\right]_{\mathrm{m}, \mathrm{m}}$ is the rotor inductance matrix, $\left[\mathrm{M}_{\mathrm{sr}}(\theta)\right]_{3, \mathrm{~m}}$ is the stator to rotor mutual inductance matrix, $\left[\mathrm{M}_{\mathrm{rs}}(\theta)\right]_{\mathrm{m}, 3}$ is the rotor to stator mutual inductance matrix and $\left[\mathrm{L}_{\mathrm{rr}}\right]_{\mathrm{m}, \mathrm{m}}$ is the rotor inductance matrix.

For the non-linear case where the magnetic saturation effect is taken into account, the stator and rotor fluxes are functions of the motor angle $\theta$, the stator and the rotor currents.

$$
[\phi]_{\mathrm{m}+3}=[\phi]_{\mathrm{m}+3}\left(\theta,[\mathrm{I}]_{\mathrm{m}+3}\right)
$$

In this case, it is difficult to find the fluxes analytically, but they can be calculated using a finite elements calculation program, in which the magnetic characteristics of the motor material can be introduced, Fig. 4 . The calculation of the fluxes as functions of the motor

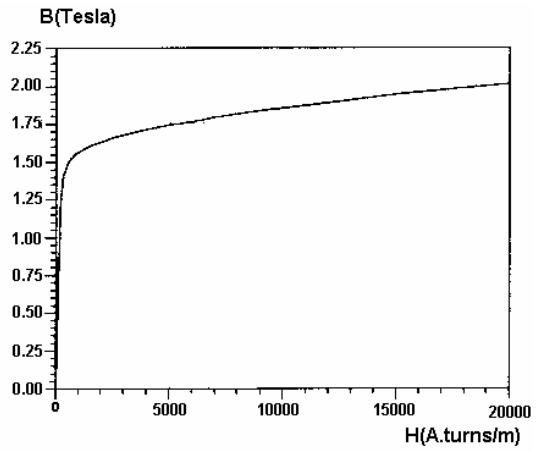

Fig. 4. Iron magnetic characteristics of the $45(\mathrm{KW})$ motor 
angle $\theta$ and the currents is possible using the concept of equivalent saturated inductances deduced from the saturation curve of the motor material.

A finite elements calculation program is used to determine the main variable that influences the magnetic state of the induction motor in a two-phase reference related to the rotor, Fig. 5.

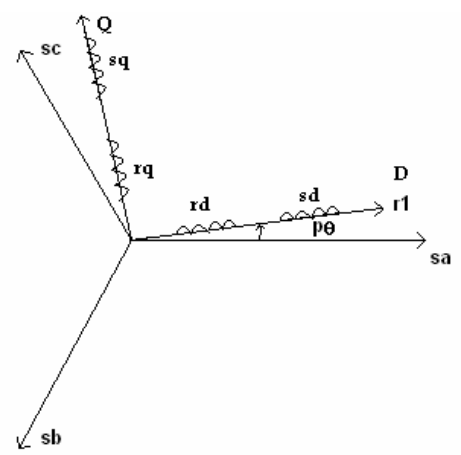

Fig. 5. Two-phase reference related to the rotor

The currents are applied in the two-phase reference, and then the currents $[\mathrm{I}]_{\mathrm{m}+3}$ are calculated using the inversed Park transformation. These currents are injected in the motor finite elements model, and the program calculates the fluxes $[\phi]_{\mathrm{m}+3}$. The fluxes in the twophase reference are finally calculated by applying the Park transformation. The calculation procedure is shown in Fig. 6.

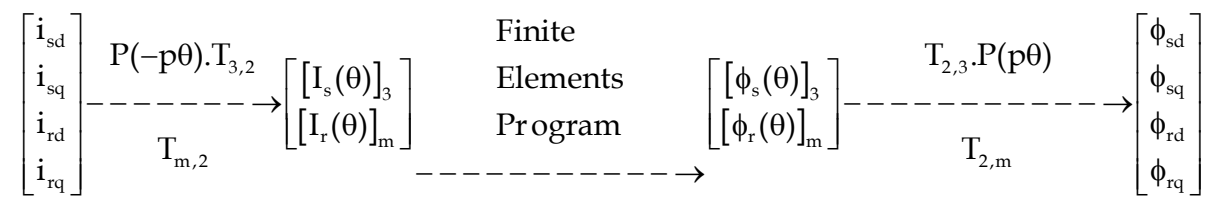

Fig. 6. Calculation procedure of the two-phase fluxes

Where $\mathrm{T}_{3,2}=\sqrt{\frac{2}{3}}\left[\begin{array}{cc}1 & 0 \\ -\frac{1}{2} & \frac{\sqrt{3}}{2} \\ -\frac{1}{2} & -\frac{\sqrt{3}}{2}\end{array}\right], \quad \mathrm{T}_{\mathrm{m}, 2}=\sqrt{\frac{2}{\mathrm{~m}}}\left[\begin{array}{cc}1 & 0 \\ \cos \left(\frac{2 \pi}{\mathrm{m}}\right) & \sin \left(\frac{2 \pi}{\mathrm{m}}\right) \\ \cdot & \cdot \\ \cdot \\ \cdot \\ \cos \left((\mathrm{m}-1) \frac{2 \pi}{\mathrm{m}}\right) & \sin \left((\mathrm{m}-1) \frac{2 \pi}{\mathrm{m}}\right)\end{array}\right]$ are the Concordia matrices, and $\mathrm{P}(\psi)=\left[\begin{array}{cc}\cos (\psi) & \sin (\psi) \\ -\sin (\psi) & \cos (\psi)\end{array}\right]$ is the rotation matrix.

The simulations show that the magnetic state of the induction motor depends on the modulus of the magnetizing current vector $\left|\overline{\mathrm{I}_{\mathrm{m}}}\right|=\sqrt{\left(\mathrm{i}_{\mathrm{sd}}+\mathrm{i}_{\mathrm{rd}}\right)^{2}+\left(\mathrm{i}_{\mathrm{sq}}+\mathrm{i}_{\mathrm{rq}}\right)^{2}}$. The magnetizing 
current vector can be written using complex representation as follows: $\overline{\mathrm{I}_{\mathrm{m}}}=\left(\mathrm{i}_{\mathrm{sd}}+\mathrm{i}_{\mathrm{rd}}\right)+\mathrm{j} .\left(\mathrm{i}_{\mathrm{sq}}+\mathrm{i}_{\mathrm{rq}}\right)$. Fig. 7 shows the magnetic state of the motor for different twophase currents that give the same value of $\left|\overline{\mathrm{I}_{\mathrm{m}}}\right|$.
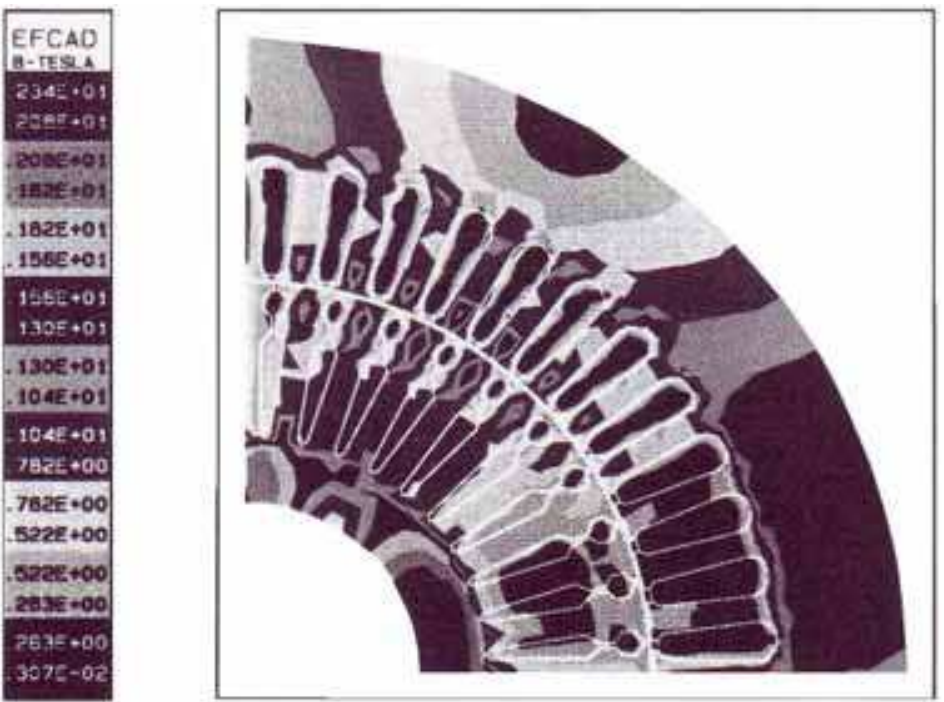

(isd, ird, isq. irq) $=(50$ (A), 380(A), 25(A), 353(A)) $\| \mathrm{m} \mid=100$ (A)
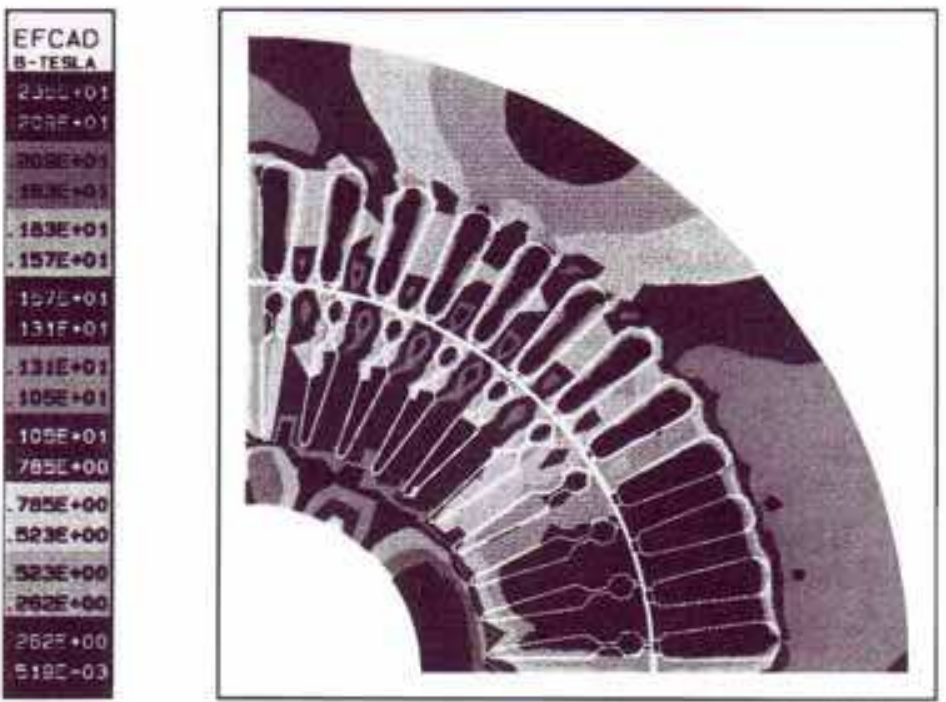

(isd, ird, isq, irq) $=(35[\mathrm{~A}), 300\{\mathrm{~A}), 40(\mathrm{~A}), 450(\mathrm{~A}))[\mathrm{im}]=100(\mathrm{~A})$

Fig. 7. Magnetic state of the motor for different two-phase currents of the same $\left|\overline{I_{m}}\right|$ 
The flux-current relationship can then be written, in the two-phase reference, as follows:

$$
\left[\begin{array}{c}
\phi_{\mathrm{sd}} \\
\phi_{\mathrm{sq}} \\
\phi_{\mathrm{rd}} \\
\phi_{\mathrm{rq}}
\end{array}\right]=\left[\begin{array}{cccc}
\mathrm{L}_{\mathrm{s}}\left(\left|\overline{\mathrm{I}_{\mathrm{m}}}\right|\right) & 0 & \mathrm{M}\left(\overline{\mathrm{I}_{\mathrm{m}}}\right) & 0 \\
0 & \mathrm{~L}_{\mathrm{s}}\left(\overline{\mathrm{I}_{\mathrm{m}}}\right) & 0 & \mathrm{M}\left(\overline{\mathrm{I}_{\mathrm{m}}}\right) \\
\mathrm{M}\left(\overline{\mathrm{I}_{\mathrm{m}}}\right) & 0 & \mathrm{~L}_{\mathrm{r}}\left(\overline{\mathrm{I}_{\mathrm{m}}}\right) & 0 \\
0 & \mathrm{M}\left(\overline{\mathrm{I}_{\mathrm{m}}}\right) & 0 & \mathrm{~L}_{\mathrm{r}}\left(\overline{\mathrm{I}_{\mathrm{m}}}\right)
\end{array}\right] \cdot\left[\begin{array}{c}
\mathrm{i}_{\mathrm{sd}} \\
\mathrm{i}_{\mathrm{sq}} \\
\mathrm{i}_{\mathrm{rd}} \\
\mathrm{i}_{\mathrm{rq}}
\end{array}\right]=[\phi]=\left[\mathrm{M}\left(\overline{\mathrm{I}_{\mathrm{m}}} \mid\right)\right] \cdot[\mathrm{I}]
$$

It is possible to obtain the cyclic inductances curves as functions of $\left|\overline{\mathrm{I}_{\mathrm{m}}}\right|$, by injecting one two-phase current. Fig. 8 shows the cyclic inductances curves as function of this injected current.

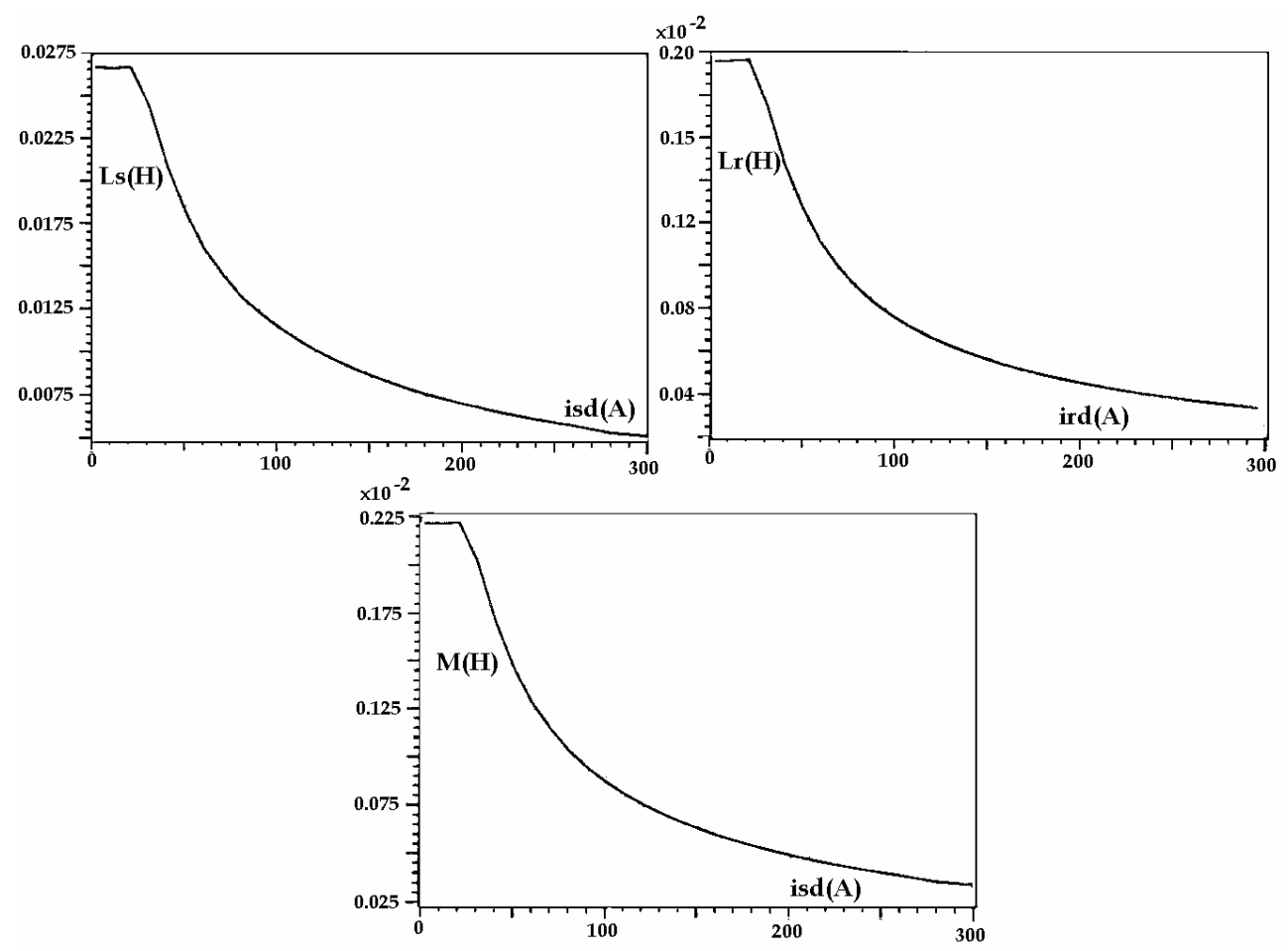

Fig. 8. Cyclic inductances curves

From these curves, inductances lookup tables are established. The values of the injected current can be associated to $\left|\overline{\mathrm{I}_{\mathrm{m}}}\right|$ (Kasmieh, T. \& Lefevre, Y. 1998).

It is important to mention that the saturation harmonics disappear from the two-phase fluxes. This issue can be demonstrated taking into accounts the saturation third harmonics of the fluxes: 


$$
\begin{aligned}
& \phi_{\mathrm{sa}}=\quad \mathrm{a} \cdot \cos (\mathrm{p} \theta)+\mathrm{b} \cdot \cos (3 \mathrm{p} \theta) \\
& \phi_{\mathrm{sb}}=a \cdot \cos \left(\mathrm{p} \theta-\frac{2 \pi}{3}\right)+b \cdot \cos \left(3 \mathrm{p} \theta-\frac{6 \pi}{3}\right) \\
& \phi_{\mathrm{sc}}=\mathrm{a} \cdot \cos \left(\mathrm{p} \theta-\frac{4 \pi}{3}\right)+\mathrm{b} \cdot \cos \left(3 \mathrm{p} \theta-\frac{12 \pi}{3}\right)
\end{aligned}
$$

Two-phase stator fluxes can be obtained by applying Park transformation of an angle p $\theta$ :

$$
\begin{gathered}
{\left[\begin{array}{c}
\phi_{\mathrm{sd}} \\
\phi_{\mathrm{sq}}
\end{array}\right]=\sqrt{\frac{2}{3}}\left[\begin{array}{ccc}
\cos (\mathrm{p} \theta) & \cos \left(\mathrm{p} \theta-\frac{2 \pi}{3}\right) & \cos \left(\mathrm{p} \theta-\frac{4 \pi}{3}\right) \\
-\sin (\mathrm{p} \theta) & -\sin \left(\mathrm{p} \theta-\frac{2 \pi}{3}\right) & -\sin \left(\mathrm{p} \theta-\frac{4 \pi}{3}\right)
\end{array}\right] \cdot\left[\begin{array}{c}
\phi_{\mathrm{sa}} \\
\phi_{\mathrm{sb}} \\
\phi_{\mathrm{sc}}
\end{array}\right]} \\
{\left[\begin{array}{l}
\phi_{\mathrm{sd}} \\
\phi_{\mathrm{sq}}
\end{array}\right]=\sqrt{\frac{2}{3}}\left[\begin{array}{c}
\frac{3 \mathrm{a}}{2}+\frac{\mathrm{a}+\mathrm{b}}{2}\left(\cos (2 \mathrm{p} \theta)+\cos \left(2 \mathrm{p} \theta-\frac{4 \pi}{3}\right)+\cos \left(2 \mathrm{p} \theta-\frac{8 \pi}{3}\right)\right)+ \\
\frac{\mathrm{b}-\mathrm{a}}{2}\left(\sin (2 \mathrm{p} \theta)+\sin \left(2 \mathrm{p} \theta-\frac{4 \pi}{3}\right)+\sin \left(2 \mathrm{p} \theta-\frac{8 \pi}{3}\right)\right)+ \\
-\frac{\mathrm{b}}{2}\left(\sin (4 \mathrm{p} \theta)+\sin \left(4 \mathrm{p} \theta-\frac{8 \pi}{3}\right)+\sin \left(4 \mathrm{p} \theta-\frac{16 \pi}{3}\right)\right)
\end{array}\right]=\left[\begin{array}{c}
\sqrt{\frac{3}{2}} \\
0
\end{array}\right]}
\end{gathered}
$$

The demonstration can be extended to the general expressions of the saturated fluxes.

The next paragraph presents a new dynamic model of the induction motor that takes into account the variation of the saturation level. The resolution of the non-linear equations of the model is done by iteration.

\section{Establishment of a saturated two-phase model of the induction motor}

Since the magnetic state of the induction motor depends on the modulus of the magnetizing current vector, thus, the new equations that describe the dynamic behavior of a variable saturation level motor in the two-phase reference are:

The electric equations:

$$
\begin{array}{lc}
\mathrm{v}_{\mathrm{sd}}=\mathrm{R}_{\mathrm{s}} \cdot \mathrm{i}_{\mathrm{sd}}+\frac{\mathrm{d} \Phi_{\mathrm{sd}}}{\mathrm{dt}}-\frac{\mathrm{d} \psi}{\mathrm{dt}} \cdot \Phi_{\mathrm{sq}} & \\
\mathrm{v}_{\mathrm{sq}}=\mathrm{R}_{\mathrm{s}} \cdot \mathrm{i}_{\mathrm{sq}}+\frac{\mathrm{d} \Phi_{\mathrm{sq}}}{\mathrm{dt}}+\frac{\mathrm{d} \psi}{\mathrm{dt}} \cdot \Phi_{\mathrm{sd}} \quad \overline{\mathrm{V}}_{\mathrm{s}}=\mathrm{R}_{\mathrm{s}} \cdot \overline{\mathrm{I}}_{\mathrm{s}}+\frac{\mathrm{d} \Phi_{\mathrm{s}}}{\mathrm{dt}}+\mathrm{j} \cdot \frac{\mathrm{d} \psi}{\mathrm{dt}} \cdot \Phi_{\mathrm{s}} \\
0=\mathrm{R}_{\mathrm{r}} \mathrm{i}_{\mathrm{rd}}+\frac{\mathrm{d} \Phi_{\mathrm{rd}}}{\mathrm{dt}}-\frac{\mathrm{d}(\psi-\mathrm{p} \theta)}{\mathrm{dt}} \cdot \Phi_{\mathrm{rq}} \quad \overline{0}=\mathrm{R}_{\mathrm{r}} \cdot \overline{\mathrm{I}}_{\mathrm{r}}+\frac{\mathrm{d} \Phi_{\mathrm{r}}}{\mathrm{dt}}+\mathrm{j} \cdot \frac{\mathrm{d}(\psi-\mathrm{p} \theta)}{\mathrm{dt}} \cdot \overline{\Phi_{\mathrm{r}}} \\
0=\mathrm{R}_{\mathrm{r}} \cdot \mathrm{i}_{\mathrm{rq}}+\frac{\mathrm{d} \Phi_{\mathrm{rq}}}{\mathrm{dt}}+\frac{\mathrm{d}(\psi-\mathrm{p} \theta)}{\mathrm{dt}} \cdot \Phi_{\mathrm{rd}} &
\end{array}
$$

The flux-current relationships:

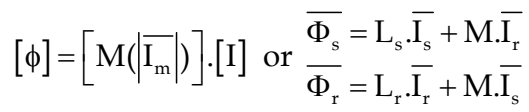


The mechanical equation: $\mathrm{j} \frac{\mathrm{d} \Omega}{\mathrm{dt}}=\mathrm{T}_{\mathrm{em}}-\mathrm{T}_{\mathrm{r}}$

where

$$
\mathrm{T}_{\mathrm{em}}=\mathrm{p} \frac{\mathrm{M}}{\mathrm{L}_{\mathrm{r}}}\left(\overline{\Phi_{\mathrm{r}}} \wedge \overline{\mathrm{I}_{\mathrm{s}}}\right)=\mathrm{p} \frac{\mathrm{M}}{\mathrm{L}_{\mathrm{r}}}\left(\Phi_{\mathrm{rd}} \cdot \mathrm{i}_{\mathrm{sd}}-\Phi_{\mathrm{rq}} \cdot \mathrm{i}_{\mathrm{sd}}\right)
$$

is the electromagnetic torque and $T_{r}$ is the resistive torque. $R_{s}$ and $R_{r}$ are the stator and the rotor windings resistances. $\mathrm{V}_{\mathrm{sd}}$ and $\mathrm{V}_{\mathrm{sq}}$ are the stator two-phase voltages and $\mathrm{J}$ is the rotor inertia.

The resistive torque is the sum of the viscosity resistive torque, and a resistive torque $T_{s}: T_{r}=f . \Omega+T_{s}$, where $f$ is the viscosity factor. Usually, the variations of $T_{s}$ are considered smaller than the variation of the velocity when controlling the motor. Note that the complex quantity $\bar{X}=x_{d}+j \cdot x_{q}$ is used to represents the vectors in the $D, Q$ reference.

The numeric resolution of the new saturated two-phase model equations is done avoiding the complicated development of the equations as currents deferential equations. The following differential equations can simply be written.

$$
\begin{gathered}
\frac{\mathrm{d}[\Phi]}{\mathrm{dt}}+\mathrm{A}\left(\mid \overline{\mathrm{I}_{\mathrm{m}}}\right) \cdot[\Phi]=[\mathrm{v}] \\
{\left[\begin{array}{cccc}
\frac{\mathrm{R}_{\mathrm{s}}}{\sigma \cdot \mathrm{L}_{\mathrm{s}}} & 0 & -\frac{\mathrm{M} \cdot \mathrm{R}_{\mathrm{s}}}{\sigma \cdot \mathrm{L}_{\mathrm{s}} \cdot \mathrm{L}_{\mathrm{r}}} & 0 \\
0 & \frac{\mathrm{R}_{\mathrm{s}}}{\sigma \cdot \mathrm{L}_{\mathrm{s}}} & 0 & -\frac{\mathrm{M} \cdot \mathrm{R}_{\mathrm{s}}}{\sigma \cdot \mathrm{L}_{\mathrm{s}} \cdot \mathrm{L}_{\mathrm{r}}} \\
-\frac{\mathrm{M} \cdot \mathrm{R}_{\mathrm{r}}}{\sigma \cdot \mathrm{L}_{\mathrm{s}} \cdot \mathrm{L}_{\mathrm{r}}} & 0 & \frac{\mathrm{R}_{\mathrm{r}}}{\sigma \cdot \mathrm{L}_{\mathrm{r}}} & \frac{\mathrm{d}(\mathrm{p} \cdot \theta)}{\mathrm{dt}} \\
0 & -\frac{\mathrm{M} \cdot \mathrm{R}_{\mathrm{r}}}{\sigma \cdot \mathrm{L}_{\mathrm{s}} \cdot \mathrm{L}_{\mathrm{r}}} & -\frac{\mathrm{d}(\mathrm{p} \cdot \theta)}{\mathrm{dt}} & \frac{\mathrm{R}_{\mathrm{r}}}{\sigma \cdot \mathrm{L}_{\mathrm{r}}}
\end{array}\right]\left(\overline{\mathrm{I}_{\mathrm{m}}}\right)}
\end{gathered}
$$

The matrix A is written for a two-phase reference related to the stator $\Psi=0$. $\sigma=1-\mathrm{M}^{2} /\left(\mathrm{L}_{\mathrm{s}} \cdot \mathrm{L}_{\mathrm{r}}\right)$ is the dispersion factor which is never equal to zero because the leakage inductances.

The new non-linear model of the induction motor is described by equations (3), (7) and the expression of the electromagnetic torque. This model is called the saturated two-phase model.

The numeric resolution procedure of these equations starts from an initial state. At each calculation step equation (7) is solved using for example Runge-Kutta 4 (RK4) method. This will give a new flux vector that describes a new magnetic state of the motor. Then, the corresponding current vector must be determined by resolving equation (3). In fact, equation (3) is a non-linear equation. The matrix $M$ depends on the modulus magnetizing current vector. The resolution of this equation can be done by a non-linear iterative resolution method, like substitution method.

Equation (7) can be written as follows: 


$$
\frac{\mathrm{d}[\Phi]}{\mathrm{dt}}=\left[\mathrm{F}\left([\Phi]_{\mathrm{t}},[\mathrm{I}]_{\mathrm{t}}\right)\right]=[\mathrm{F}]_{\mathrm{t}}
$$

where $[\mathrm{F}]_{\mathrm{t}}$ is a function of the two-phase fluxes and currents.

The RK4 method gives an approximated numerical solution of equation (9). The fluxes at the instant $\mathrm{t}+\Delta \mathrm{t}$ are calculated using equation (10).

$$
[\Phi]_{\mathrm{t}+\Delta \mathrm{t}}=[\Phi]_{\mathrm{t}}+\sum_{\mathrm{i}=1}^{4} \mathrm{~b}_{\mathrm{i}} \cdot \Delta \mathrm{t}[\mathrm{F}]_{\mathrm{i}}
$$

where

$$
\begin{aligned}
& {[\Phi]_{1}=[\Phi]_{\mathrm{t}}+\frac{\Delta \mathrm{t}}{2}[\mathrm{~F}]_{1}=[\Phi]_{\mathrm{t}}+\frac{\Delta \mathrm{t}}{2}[\mathrm{~F}]_{\mathrm{t}}} \\
& {[\Phi]_{2}=[\Phi]_{1}+\frac{\Delta \mathrm{t}}{2}[\mathrm{~F}]_{2}=[\Phi]_{1}+\frac{\Delta \mathrm{t}}{2}\left[\mathrm{~F}\left([\Phi]_{1},[\mathrm{I}]_{1}\right)\right]} \\
& {[\Phi]_{3}=[\Phi]_{2}+\frac{\Delta \mathrm{t}}{2}[\mathrm{~F}]_{3}=[\Phi]_{2}+\frac{\Delta \mathrm{t}}{2}\left[\mathrm{~F}\left([\Phi]_{2},[\mathrm{I}]_{2}\right)\right]} \\
& {[\Phi]_{4}=[\Phi]_{3}+\frac{\Delta \mathrm{t}}{2}[\mathrm{~F}]_{4}=[\Phi]_{3}+\frac{\Delta \mathrm{t}}{2}\left[\mathrm{~F}\left([\Phi]_{3},[\mathrm{I}]_{3}\right)\right]}
\end{aligned}
$$

and $b_{1}=\frac{1}{6}, b_{2}=\frac{1}{3}, b_{3}=\frac{1}{6}, b_{4}=\frac{1}{6}$.

To be able to calculate $[\Phi]_{\mathrm{i}+1}$, the currents $[\mathrm{I}]_{\mathrm{i}}$ must be calculated by solving the non-linear equation $[\phi]_{\mathrm{i}}=\left[\mathrm{M}\left(\left|\overline{\mathrm{I}_{\mathrm{m}}}\right|_{\mathrm{i}}\right)\right] \cdot[\mathrm{I}]_{\mathrm{i}}$. Finally, Fig. 9 shows the calculation procedure of the saturated two-phase model of the induction motor.

The resolution of the non-linear equations of the flux-current relationships can be done using a non-linear iterative resolution method. The substitution method searches the intersection point between $\left(\left[\mathrm{M}\left(\left|\overline{\mathrm{I}_{\mathrm{m}}}\right|\right)\right] \cdot[\mathrm{I}]\right)(\mathrm{t})$ and $[\phi]_{\mathrm{t}+\Delta t}$ starting from the first iteration $[\mathrm{I}]_{1}=[\mathrm{I}]_{\mathrm{t}}$. The next iteration is calculated from the previous iteration: $[\mathrm{I}]_{\mathrm{i}+1}=[\mathrm{I}]_{\mathrm{i}}+\Delta[\mathrm{I}]$, where $\Delta[\mathrm{I}]=\left[\mathrm{M}\left(\left|\overline{\mathrm{I}_{\mathrm{m}}}\right|_{\mathrm{i}}\right)\right]^{-1} \cdot\left([\Phi]_{\mathrm{t}+\Delta \mathrm{t}}-\mathrm{M}\left(\left|\overline{\mathrm{I}_{\mathrm{m}}}\right|_{\mathrm{i}}\right) \cdot[\mathrm{I}]_{\mathrm{i}}\right)$. In fact the Inductance matrix can be inversed, since the leakage inductances cannot be zero:

$$
\left[\mathrm{M}\left(\overline{\mathrm{I}_{\mathrm{m}}}\right)\right]^{-1}=\left[\begin{array}{cccc}
\frac{1}{\sigma \cdot \mathrm{L}_{\mathrm{s}}} & 0 & -\frac{\mathrm{M}}{\sigma \cdot \mathrm{L}_{\mathrm{s}} \cdot \mathrm{L}_{\mathrm{r}}} & 0 \\
0 & \frac{1}{\sigma \cdot \mathrm{L}_{\mathrm{s}}} & 0 & -\frac{\mathrm{M}}{\sigma \cdot \mathrm{L}_{\mathrm{s}} \cdot \mathrm{L}_{\mathrm{r}}} \\
-\frac{\mathrm{M}_{\mathrm{r}}}{\sigma \cdot \mathrm{L}_{\mathrm{s}} \cdot \mathrm{L}_{\mathrm{r}}} & 0 & \frac{1}{\sigma \cdot \mathrm{L}_{\mathrm{r}}} & 0 \\
0 & -\frac{\mathrm{M}}{\sigma \cdot \mathrm{L}_{\mathrm{s}} \cdot \mathrm{L}_{\mathrm{r}}} & 0 & \frac{1}{\sigma \cdot \mathrm{L}_{\mathrm{r}}}
\end{array}\right]\left(\overline{\mathrm{I}_{\mathrm{m}}}\right)
$$

Fig. 10. shows the substitution calculation procedure for vectors dimension equal to one. 


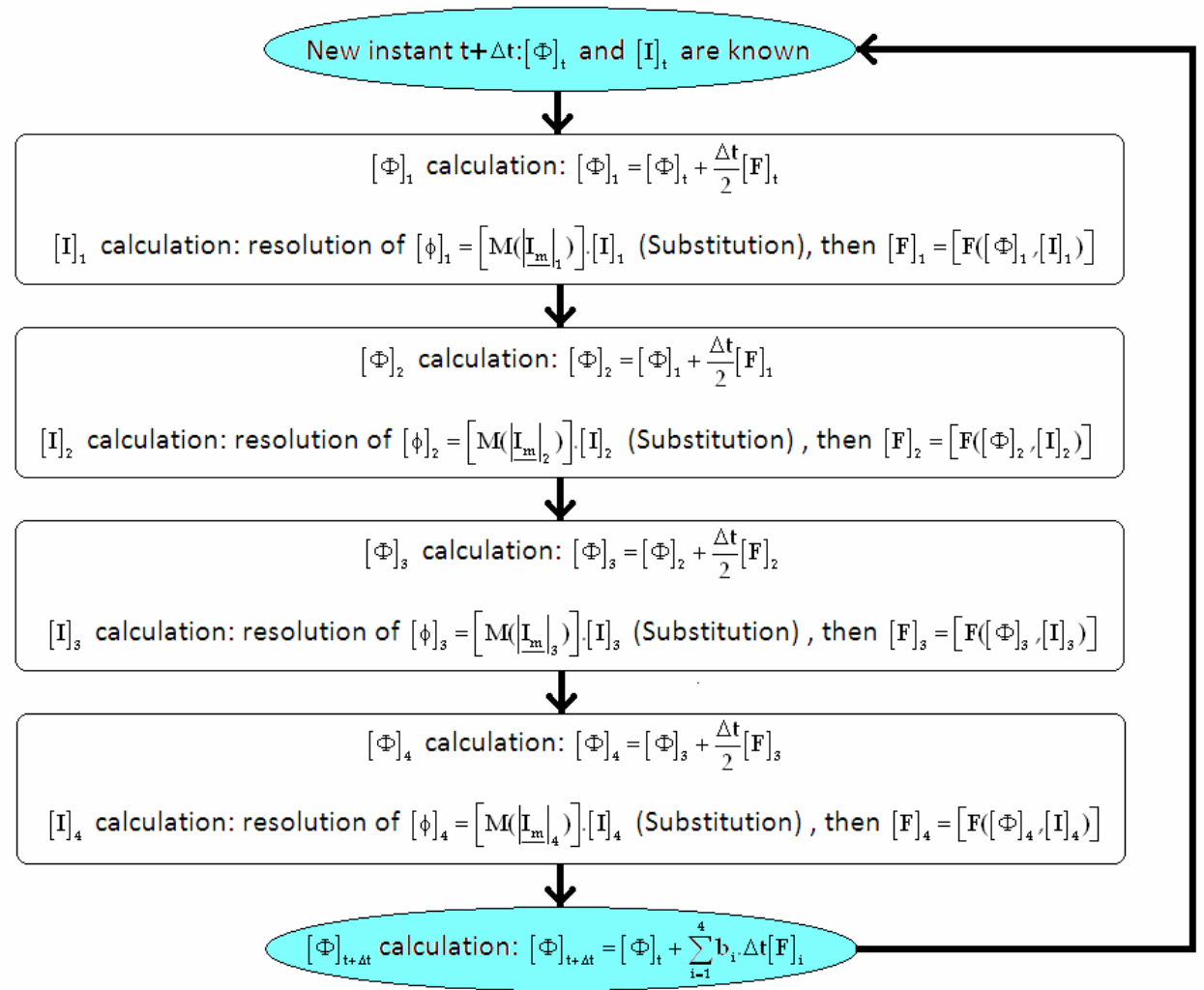

Fig. 9. Calculation procedure of the saturated two-phase model of the induction motor

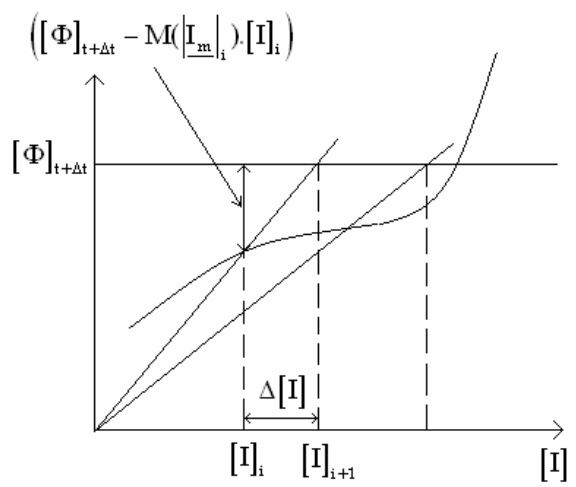

Fig. 10. Substitution calculation procedure

The iteration procedure is stopped when achieving a suitable error of the modulus of the flux vector.

The execution of the calculation procedure of the Fig. 9 gives the results shown in Fig. 11. 

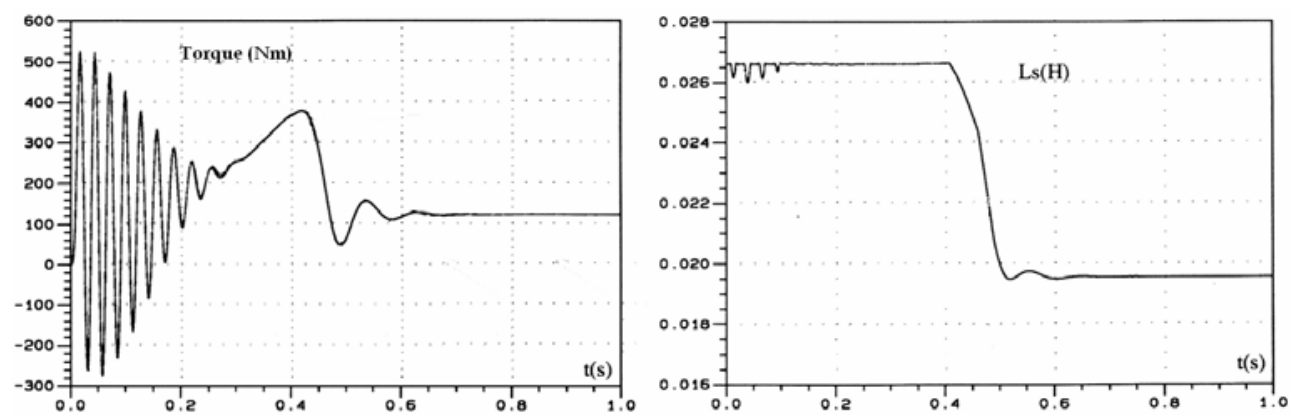

Fig. 11. Dynamic behavior of the saturated two-phase model of the induction motor

The comparison between the saturated two-phase model and the finite elements model is shown in Fig. 12. It is clear that it gives closer results to the finite elements model results than the results of the linear model.
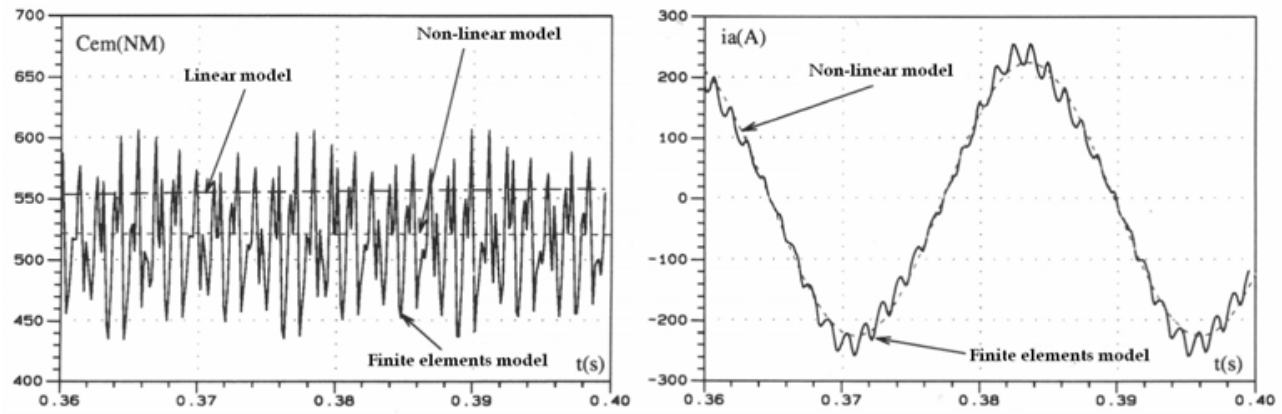

Fig. 12. Saturated two-phase model, linear model and finite element model results comparison

\section{Field oriented control law improvement during the flux weakening phase}

The vector control law or field-oriented control (FOC) law of an induction motor has become a powerful and frequently adopted technique world-wide. It is based on the twophase model, Park model. The aim of this control is to give the induction motor a dynamic behavior like the dynamic behavior of a direct current motor. This can be done by controlling separately the modulus and the phase angle of the flux (Blaschke, F. 1972).

Using this control technique, the electrical and mechanical dynamic responses of the induction motor are determined by fixing the coefficients of the current loops controllers, flux loop controller and the velocity loop controller. Usually, these coefficients are calculated for the rating values of the cyclic inductances, which correspond to the rating saturation level. In fact, this level is achieved by applying the rating flux value as a reference value to the flux loop.

Some industrial applications require the induction motor to operate at a high speed over the rating speed. The method used to reach this speed is to decrease the reference value of the flux in order to work at the rating power. This decrease can cause a coupling between the two-phase axes D and Q, so FOC does not work properly (Kasmieh, T. \& Lefevre, Y. 1998). 
Many published papers have studied the effects of the variation of the saturation level on FOC law (Vas, P. \& Alakula, M. 1990) (Vas, P. 1981), but few attempts have been made to develop a FOC law that takes into account this variation.

In this paragraph the sensitivity of the classical FOC law to the variation of saturation level of an induction motor is studied. Then, a new indirect vector control law in accordance to the rotor flux vector that takes into account this variation is developed. This law is based on the saturated two-phase model found in the previous sections.

The simulations are done using an electromechanical simulation program called "A_MOS", Asynchronous Motor Open Simulator, (Kasmieh, T. 2002), Fig. 13.

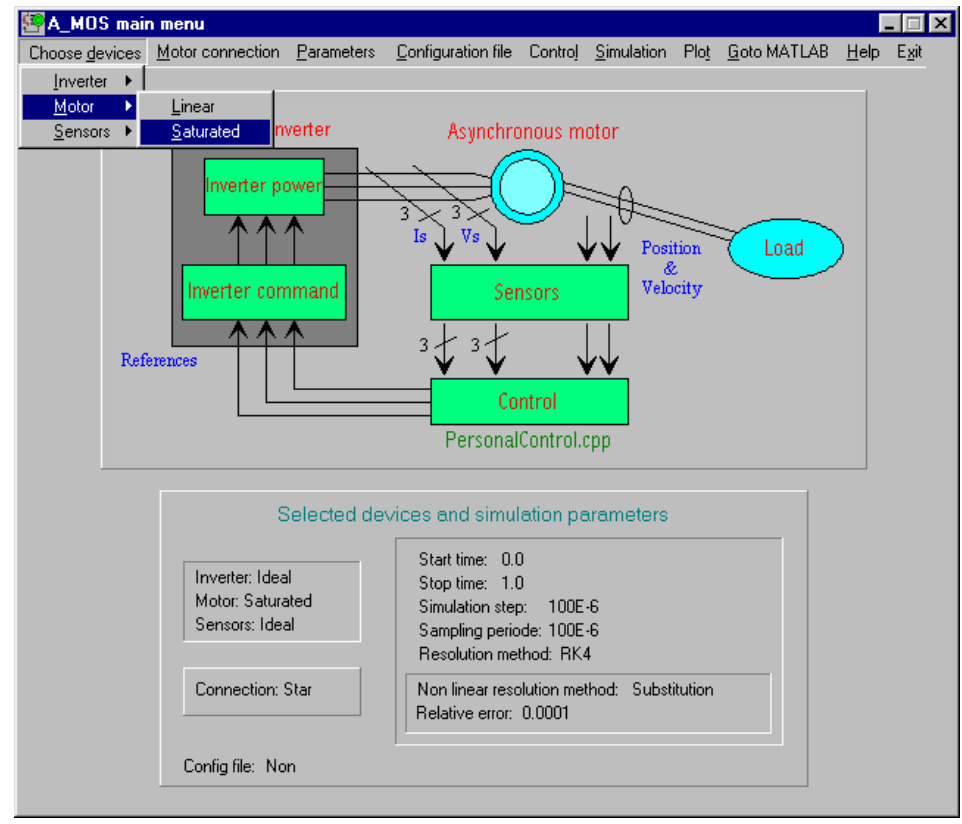

Fig. 13. The main window of "A-MOS" Software

The resolution algorithm of the non-linear model is implemented in this programmed. The user can write his own control algorithm.

\subsection{Classical FOC law}

The strategy of the FOC in accordance with the rotor flux vector is adopted. This strategy leads to simpler equations than those obtained with the axis D aligned on the stator flux vector or with the magnetizing flux vector (Vas, P. \& Alakula, M. 1990).

The development of the FOC equations in accordance to the rotor flux vector can be done by supposing $\underline{\phi_{\mathrm{r}}}=\left[\phi_{\mathrm{rd}}, \phi_{\mathrm{rq}}\right]^{\mathrm{t}}=\left[\phi_{\mathrm{r}}, 0\right]^{\mathrm{t}}$, Fig. 14. The expression of the motor torque is reduced to:

$$
\mathrm{T}_{\mathrm{em}}=\mathrm{p} \frac{\mathrm{M}}{\mathrm{L}_{\mathrm{r}}} \cdot \Phi_{\mathrm{r}} \cdot \mathrm{i}_{\mathrm{sd}}
$$

Since the rotor flux vector turns at the synchronized speed $\omega_{\mathrm{s}}$, the electric equations become: 


$$
\begin{aligned}
& \mathrm{v}_{\mathrm{sd}}=\mathrm{R}_{\mathrm{s}} \cdot \mathrm{i}_{\mathrm{sd}}+\frac{\mathrm{d} \Phi_{\mathrm{sd}}}{\mathrm{dt}}-\omega_{\mathrm{s}} \cdot \Phi_{\mathrm{sq}} \\
& \mathrm{v}_{\mathrm{sq}}=\mathrm{R}_{\mathrm{s}} \cdot \mathrm{i}_{\mathrm{sq}}+\frac{\mathrm{d} \Phi_{\mathrm{sq}}}{\mathrm{dt}}+\omega_{\mathrm{s}} \cdot \Phi_{\mathrm{sd}} \\
& 0=\mathrm{R}_{\mathrm{r}} \cdot \mathrm{i}_{\mathrm{rd}}+\frac{\mathrm{d} \Phi_{\mathrm{r}}}{\mathrm{dt}} \\
& 0=\mathrm{R}_{\mathrm{r}} \cdot \mathrm{i}_{\mathrm{rq}}+\left(\omega_{\mathrm{s}}-\mathrm{p} \frac{\mathrm{d} \theta}{\mathrm{dt}}\right) \cdot \Phi_{\mathrm{r}}
\end{aligned}
$$

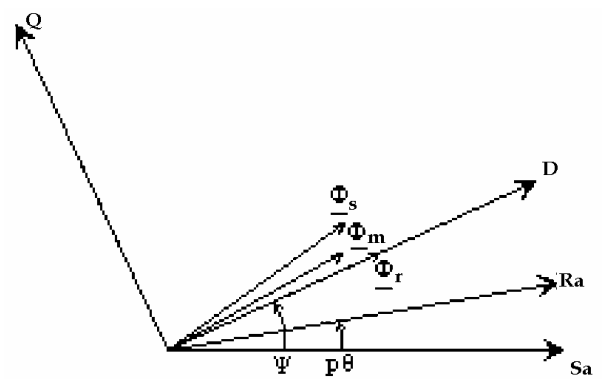

Fig. 14. Two-phase reference in accordance with the rotor flux vector

\subsubsection{Stator voltages and stator fluxes equations}

The stator voltages of equation (12), and the stator fluxes expressions can be written using complex representation $\left(\bar{X}=x_{d}+j \cdot x_{q}\right)$ :

$$
\begin{aligned}
& \overline{\mathrm{V}_{\mathrm{s}}}=\mathrm{R}_{\mathrm{s}} \cdot \overline{\mathrm{I}_{\mathrm{s}}}+\frac{\mathrm{d} \overline{\Phi_{\mathrm{s}}}}{\mathrm{dt}}+\mathrm{j} \cdot \omega_{\mathrm{s}} \cdot \overline{\Phi_{\mathrm{s}}} \\
& \overline{\Phi_{\mathrm{s}}}=\mathrm{L}_{\mathrm{s}} \cdot \overline{\mathrm{I}_{\mathrm{s}}}+\mathrm{M} \cdot \overline{\mathrm{I}}_{\mathrm{r}}
\end{aligned}
$$

By adding and subtracting the term $\frac{\mathrm{M}^{2}}{\mathrm{~L}_{\mathrm{r}}} \cdot \overline{\mathrm{I}}_{\mathrm{s}}$ in the stator flux vector expression, the magnetizing rotor current vector is introduced $\overline{\mathrm{I}_{\mathrm{mr}}}$ :

$$
\overline{\Phi_{s}}=\sigma L_{s} \cdot \overline{I_{s}}+\frac{M^{2}}{L_{r}} \cdot\left(\overline{I_{s}}+\frac{L_{r}}{M} \cdot \bar{I}_{r}\right)=\sigma L_{s} \cdot \overline{I_{s}}+\frac{M^{2}}{L_{r}} \cdot\left(\overline{I_{m r}}\right) .
$$

Since the rotor flux vector is aligned on the magnetizing rotor current vector: $\overline{\Phi_{\mathrm{r}}}=\Phi_{\mathrm{r}}=\mathrm{L}_{\mathrm{r}} \cdot \overline{\mathrm{I}}_{\mathrm{r}}+\mathrm{M} \cdot \overline{\mathrm{I}_{\mathrm{s}}}=\mathrm{M} \cdot \overline{\mathrm{I}_{\mathrm{mr}}}$, the stator flux vector can be written as a function of the stator current vector and the rotor flux.

$$
\overline{\Phi_{\mathrm{s}}}=\sigma \mathrm{L}_{\mathrm{s}} \cdot \overline{\mathrm{I}_{\mathrm{s}}}+\frac{\mathrm{M}}{\mathrm{L}_{\mathrm{r}}} \cdot \Phi_{\mathrm{r}}
$$

Substituting (13) in the expression of the stator voltage vector: 


$$
\overline{V_{s}}=R_{s} \cdot \overline{I_{s}}+\sigma L_{s} \cdot \frac{d \bar{I}_{s}}{d t}+\frac{M}{L_{r}} \cdot \frac{d \Phi_{r}}{d t}+j \cdot \omega_{s} \cdot \overline{\Phi_{s}}
$$

\subsubsection{Rotor voltages and rotor fluxes equations}

The pulsation $\left(\omega_{\mathrm{s}}-\mathrm{p} \frac{\mathrm{d} \theta}{\mathrm{dt}}\right)$ is the rotor pulsation $\omega_{\mathrm{r}}$, thus the rotor electric equations become:

$$
\begin{aligned}
& 0=\mathrm{R}_{\mathrm{r}} \cdot \mathrm{i}_{\mathrm{rd}}+\frac{\mathrm{d} \Phi_{\mathrm{r}}}{\mathrm{dt}} \\
& 0=\mathrm{R}_{\mathrm{r}} \cdot \mathrm{i}_{\mathrm{rq}}+\omega_{\mathrm{r}} \cdot \Phi_{\mathrm{r}}
\end{aligned}
$$

From the rotor fluxes expressions, the rotor currents are expressed as functions of the rotor flux and the stator currents:

$$
\begin{gathered}
\begin{array}{c}
\phi_{\mathrm{rd}}=\mathrm{L}_{\mathrm{r}} \cdot \mathrm{i}_{\mathrm{rd}}+\mathrm{M} \cdot \mathrm{i}_{\mathrm{sd}} \\
\phi_{\mathrm{rq}}=\mathrm{L}_{\mathrm{r}} \cdot \mathrm{i}_{\mathrm{rq}}+\mathrm{M} \cdot \mathrm{i}_{\mathrm{sq}}
\end{array} \quad \begin{array}{c}
\phi_{\mathrm{r}}=\mathrm{L}_{\mathrm{r}} \cdot \mathrm{i}_{\mathrm{rd}}+\mathrm{M} \cdot \mathrm{i}_{\mathrm{sd}} \\
0=\mathrm{L}_{\mathrm{r}} \cdot \mathrm{i}_{\mathrm{rq}}+\mathrm{M} \cdot \mathrm{i}_{\mathrm{sq}}
\end{array} \Rightarrow \\
\mathrm{i}_{\mathrm{rd}}=\frac{\phi_{\mathrm{r}}}{\mathrm{L}_{\mathrm{r}}}-\frac{\mathrm{M}}{\mathrm{L}_{\mathrm{r}}} \cdot \mathrm{i}_{\mathrm{sd}} \\
\mathrm{i}_{\mathrm{rq}}=-\frac{\mathrm{M}}{\mathrm{L}_{\mathrm{r}}} \cdot \mathrm{i}_{\mathrm{sq}}
\end{gathered}
$$

\subsubsection{Transfer functions of the induction motor}

In order to establish the FOC strategy, the transfer functions of the motor are developed. The inputs of the transfer functions are $\mathrm{v}_{\mathrm{sd}}$ and $\mathrm{v}_{\mathrm{sq}}$, and the outputs the variables that determine the motor torque $\Phi_{\mathrm{r}}$ and $\mathrm{i}_{\mathrm{sd}}$.

\section{Transfer functions on $D$ axis:}

It is possible to control the rotor flux via the stator current on the $\mathrm{D}$ axis. This can be demonstrated from the rotor electric equation on the $\mathrm{D}$ axis and from equation (16):

$$
\frac{\mathrm{d} \Phi_{\mathrm{r}}}{\mathrm{dt}}=-\frac{\mathrm{R}_{\mathrm{r}}}{\mathrm{L}_{\mathrm{r}}} \cdot \Phi_{\mathrm{r}}+\mathrm{R}_{\mathrm{r}} \cdot \frac{\mathrm{M}}{\mathrm{L}_{\mathrm{r}}} \cdot \mathrm{i}_{\mathrm{sd}}
$$

Developing equation (14) on the axis D yields to:

$$
\mathrm{v}_{\mathrm{sd}}=\mathrm{R}_{\mathrm{s}} \cdot \mathrm{i}_{\mathrm{sd}}+\sigma \mathrm{L}_{\mathrm{s}} \cdot \frac{\mathrm{di}_{\mathrm{sd}}}{\mathrm{dt}}+\frac{\mathrm{M}}{\mathrm{L}_{\mathrm{r}}} \cdot \frac{\mathrm{d} \Phi_{\mathrm{r}}}{\mathrm{dt}}-\omega_{\mathrm{s}} \cdot \Phi_{\mathrm{sq}}
$$

By substituting equation (17) in the expression of $\Phi_{\mathrm{sq}}$, the following equation is obtained:

$$
\phi_{\mathrm{sq}}=\mathrm{L}_{\mathrm{s}} \cdot \mathrm{i}_{\mathrm{sq}}+\mathrm{M} \cdot \mathrm{i}_{\mathrm{rq}}=\mathrm{L}_{\mathrm{s}} \cdot \mathrm{i}_{\mathrm{sq}}-\frac{\mathrm{M}^{2}}{\mathrm{~L}_{\mathrm{r}}} \cdot \mathrm{i}_{\mathrm{sq}}=\left(\mathrm{L}_{\mathrm{s}}-\frac{\mathrm{M}^{2}}{\mathrm{~L}_{\mathrm{r}}}\right) \cdot \mathrm{i}_{\mathrm{sq}}=\mathrm{L}_{\mathrm{s}} \cdot\left(1-\frac{\mathrm{M}^{2}}{\mathrm{~L}_{\mathrm{r}} \cdot \mathrm{L}_{\mathrm{s}}}\right) \cdot \mathrm{i}_{\mathrm{sq}}=\mathrm{L}_{\mathrm{s}} \cdot \sigma \cdot \mathrm{i}_{\mathrm{sq}} \cdot
$$

The D stator voltage expression becomes: 


$$
\mathrm{v}_{\mathrm{sd}}=\mathrm{R}_{\mathrm{s}} \cdot \mathrm{i}_{\mathrm{sd}}+\sigma \mathrm{L}_{\mathrm{s}} \cdot \frac{\mathrm{di}_{\mathrm{sd}}}{\mathrm{dt}}+\frac{\mathrm{M}}{\mathrm{L}_{\mathrm{r}}} \cdot \frac{\mathrm{d} \Phi_{\mathrm{r}}}{\mathrm{dt}}-\omega_{\mathrm{s}} \cdot \mathrm{L}_{\mathrm{s}} \cdot \sigma \cdot \mathrm{i}_{\mathrm{sq}}
$$

By replacing (18) in (19), the stator voltage of the D axis can be written as follows:

$$
\mathrm{v}_{\mathrm{sd}}=\mathrm{R}_{\mathrm{sr}} \cdot \mathrm{i}_{\mathrm{sd}}+\sigma \mathrm{L}_{\mathrm{s}} \cdot \frac{\mathrm{di}}{\mathrm{dt}}+\mathrm{E}_{\mathrm{d}}
$$

where $R_{s r}=R_{s}+R_{r} \cdot\left(\frac{M}{L_{r}}\right)^{2}$, and the electrical force $E_{d}=-R_{r} \cdot \frac{M}{L_{r}^{2}} \cdot \Phi_{r}-\omega_{s} \cdot L_{s} \cdot \sigma \cdot i_{s q}$ represents the coupling between the two axes $\mathrm{D}$ and $\mathrm{Q}$.

\section{Transfer functions on $\mathbf{Q}$ axis:}

By developing equation (14) on the axis $Q$, the stator voltage of the same axis is obtained:

$$
\mathrm{v}_{\mathrm{sq}}=\mathrm{R}_{\mathrm{s}} \cdot \mathrm{i}_{\mathrm{sq}}+\sigma \mathrm{L}_{\mathrm{s}} \cdot \frac{\mathrm{di}_{\mathrm{sq}}}{\mathrm{dt}}+\omega_{\mathrm{s}} \cdot \Phi_{\mathrm{sd}}
$$

From equation (13) the D stator flux is: $\Phi_{s d}=\sigma L_{s} \cdot i_{s d}+\frac{M}{L_{r}} \cdot \Phi_{r}$. By replacing $\Phi_{\text {sd }}$ in the previous expression, $\mathrm{v}_{\mathrm{sq}}$ becomes:

$$
\mathrm{v}_{\mathrm{sq}}=\mathrm{R}_{\mathrm{s}} \cdot \mathrm{i}_{\mathrm{sq}}+\sigma \mathrm{L}_{\mathrm{s}} \cdot \frac{\mathrm{di}_{\mathrm{sq}}}{\mathrm{dt}}+\omega_{\mathrm{s}} \cdot \sigma \mathrm{L}_{\mathrm{s}} \cdot \mathrm{i}_{\mathrm{sd}}+\omega_{\mathrm{s}} \cdot \frac{\mathrm{M}}{\mathrm{L}_{\mathrm{r}}} \cdot \Phi_{\mathrm{r}}
$$

$\Phi_{\mathrm{r}}$ can be written as a function of the stator current on the $\mathrm{Q}$ axis by substituting the expression of $\mathrm{i}_{\mathrm{rq}}$, equation (17), in the rotor electric equation on the $\mathrm{Q}$ axis:

$$
\Phi_{\mathrm{r}}=\mathrm{R}_{\mathrm{r}} \cdot \frac{\mathrm{M}}{\omega_{\mathrm{r}} \cdot \mathrm{L}_{\mathrm{r}}} \mathrm{i}_{\mathrm{sq}}
$$

By replacing (22) in (21) :

$$
\begin{aligned}
& \mathrm{v}_{\mathrm{sq}}=\mathrm{R}_{\mathrm{s}} \cdot \mathrm{i}_{\mathrm{sq}}+\sigma \mathrm{L}_{\mathrm{s}} \cdot \frac{\mathrm{di}}{\mathrm{dt}}+\omega_{\mathrm{s}} \cdot \sigma \mathrm{L}_{\mathrm{s}} \cdot \mathrm{i}_{\mathrm{sd}}+\frac{\omega_{\mathrm{s}}}{\omega_{\mathrm{r}}} \cdot\left(\frac{\mathrm{M}}{\mathrm{L}_{\mathrm{r}}}\right)^{2} \cdot \mathrm{R}_{\mathrm{r}} \cdot \mathrm{i}_{\mathrm{sq}} \\
& \mathrm{v}_{\mathrm{sq}}=\mathrm{R}_{\mathrm{s}} \cdot \mathrm{i}_{\mathrm{sq}}+\sigma \mathrm{L}_{\mathrm{s}} \cdot \frac{\mathrm{di} \mathrm{i}_{\mathrm{sq}}}{\mathrm{dt}}+\omega_{\mathrm{s}} \cdot \sigma \mathrm{L}_{\mathrm{s}} \cdot \mathrm{i}_{\mathrm{sd}}+\frac{\omega+\omega_{\mathrm{r}}}{\omega_{\mathrm{r}}} \cdot\left(\frac{\mathrm{M}}{\mathrm{L}_{\mathrm{r}}}\right)^{2} \cdot \mathrm{R}_{\mathrm{r}} \cdot \mathrm{i}_{\mathrm{sq}}
\end{aligned}
$$

Finally $\mathrm{v}_{\mathrm{sq}}$ can be written as follows:

$$
\mathrm{v}_{\mathrm{sq}}=\mathrm{R}_{\mathrm{sr}} \cdot \mathrm{i}_{\mathrm{sq}}+\sigma \mathrm{L}_{\mathrm{s}} \cdot \frac{\mathrm{di}_{\mathrm{sq}}}{\mathrm{dt}}+\omega_{\mathrm{s}} \cdot \sigma \mathrm{L}_{\mathrm{s}} \cdot \mathrm{i}_{\mathrm{sd}}+\omega \cdot\left(\frac{\mathrm{M}}{\mathrm{L}_{\mathrm{r}}}\right)^{2} \cdot \mathrm{R}_{\mathrm{r}} \cdot \mathrm{i}_{\mathrm{sq}}=\mathrm{R}_{\mathrm{sr}} \cdot \mathrm{i}_{\mathrm{sq}}+\sigma \mathrm{L}_{\mathrm{s}} \cdot \frac{\mathrm{di}_{\mathrm{sq}}}{\mathrm{dt}}+\mathrm{E}_{\mathrm{q}}
$$

The electrical force $\mathrm{E}_{\mathrm{q}}$ represents the coupling between the two axes $\mathrm{D}$ and $\mathrm{Q}$.

The equations (18), (20) and (23) describe the transfer functions of the induction motor if the $\mathrm{D}$ axis is aligned on the rotor flux vector, Fig. 15. 


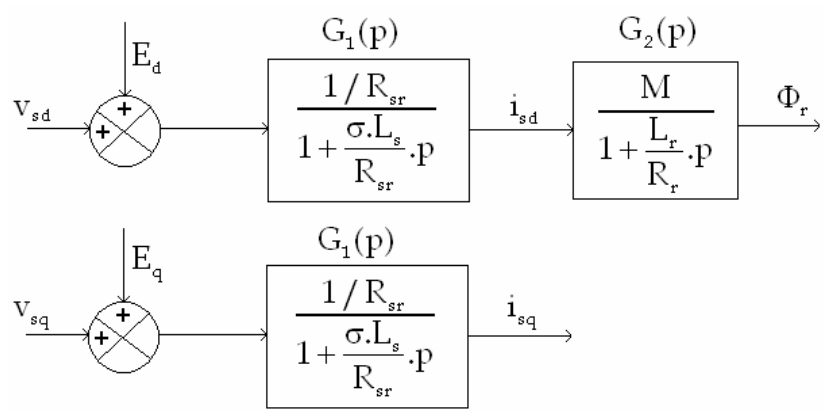

Fig. 15. Transfer functions of the induction motor ( $\mathrm{D}$ axis is aligned on the rotor flux vector)

\subsubsection{Establishment of the classical FOC law}

It is important to mention that the transfer functions shown on Fig. 15 are valid if the axis D is rotating with the rotor flux vector. Taking into account this hypothesis the control scheme of Fig. 16 can be built.

The two axes $\mathrm{D}$ and $\mathrm{Q}$ are decoupled by estimating the electric forces $\mathrm{E}_{\mathrm{d}}$ and $\mathrm{E}_{\mathrm{q}}$ $\mathrm{E}_{\mathrm{d}}^{\mathrm{e}}=-\mathrm{R}_{\mathrm{r}} \cdot \frac{\mathrm{M}}{\mathrm{L}_{\mathrm{r}}^{2}} \cdot \Phi_{\mathrm{r}}^{\mathrm{e}}-\omega_{\mathrm{s}}^{\mathrm{e}} \cdot \mathrm{L}_{\mathrm{s}} \cdot \sigma \cdot \mathrm{i}_{\mathrm{sq}}^{\mathrm{m}}$ and $\mathrm{E}_{\mathrm{q}}^{\mathrm{e}}=\omega_{\mathrm{s}}^{\mathrm{e}} \cdot \sigma \mathrm{L}_{\mathrm{s}} \cdot \mathrm{i}_{\mathrm{sd}}^{\mathrm{m}}+\omega^{\mathrm{m}} \cdot\left(\frac{\mathrm{M}}{\mathrm{L}_{\mathrm{r}}}\right)^{2} \cdot \mathrm{R}_{\mathrm{r}} \cdot \mathrm{i}_{\mathrm{sq}}^{\mathrm{m}} \cdot$ The index $\mathrm{e}$ is for the estimated variables, and the index $\mathrm{m}$ is for the measured variables.

$\Phi_{\mathrm{r}}^{\mathrm{e}}$ is calculated by solving numerically the equation (18). The value of $\Phi_{\mathrm{r}}^{\mathrm{e}}$ is also used as a feedback for the rotor flux control closed loop.

$\omega_{\mathrm{s}}^{\mathrm{e}}$ is calculated from equation (18): $\omega_{\mathrm{s}}^{\mathrm{e}}=\omega^{\mathrm{m}}+\mathrm{R}_{\mathrm{r}} \cdot \frac{\mathrm{M}}{\Phi_{\mathrm{r}}^{\mathrm{e}} \cdot \mathrm{L}_{\mathrm{r}}} \mathrm{i}_{\mathrm{sq}}^{\mathrm{m}} \cdot \omega^{\mathrm{m}}=\mathrm{p} \cdot \Omega^{\mathrm{m}}=\mathrm{p} \cdot \mathrm{d} \theta / \mathrm{dt}$ is the electric speed of the motor that can be measured using a speed sensor, and $\mathrm{p}$ is the pole pairs number.

For the induction motor, $L_{r} / R_{r}$ is ten times bigger than $\sigma . L_{s} / R_{s r}$, so it is possible to do poles separation by doing an inner closed loop for the current and an outer closed loop for the rotor flux.

From Fig. 16, it is clear that the D axis closed loops are for controlling the amplitude of the rotor flux, and the closed loop of the $\mathrm{Q}$ axis is for controlling the stator current, thus for controlling the motor torque, equation (11).

In practice, the three phase currents are measured, and then the two phase currents are calculated using Park transformation of an angle $\Psi$. The angle $\Psi$ is estimated by integrating $\omega_{\mathrm{s}}^{\mathrm{e}}=\omega^{\mathrm{m}}+\mathrm{R}_{\mathrm{r}} \cdot \frac{\mathrm{M}}{\Phi_{\mathrm{r}}^{\mathrm{e}} \cdot \mathrm{L}_{\mathrm{r}}} \mathrm{i}_{\mathrm{sq}}^{\mathrm{m}}$. After calculating the control variables $\mathrm{v}_{\mathrm{sd}}$ and $\mathrm{v}_{\mathrm{sq}}$, the three phase control variables $\mathrm{v}_{\mathrm{sa}}, \mathrm{v}_{\mathrm{sb}}$ and $\mathrm{v}_{\mathrm{sc}}$ are found using the inversed Park transformation.

\subsection{Sensitivity of the classical FOC law to the variation of the saturation level}

the FOC algorithm is implemented in "A_MOS" program. The controller parameters are fixed according to rating values of the induction motor cyclic inductances. The simulation results of fig. 17 show that during the flux weakening phase, the rotor flux does not follow its reference and the dynamic response of the speed is disturbed. This due to the fact that the 


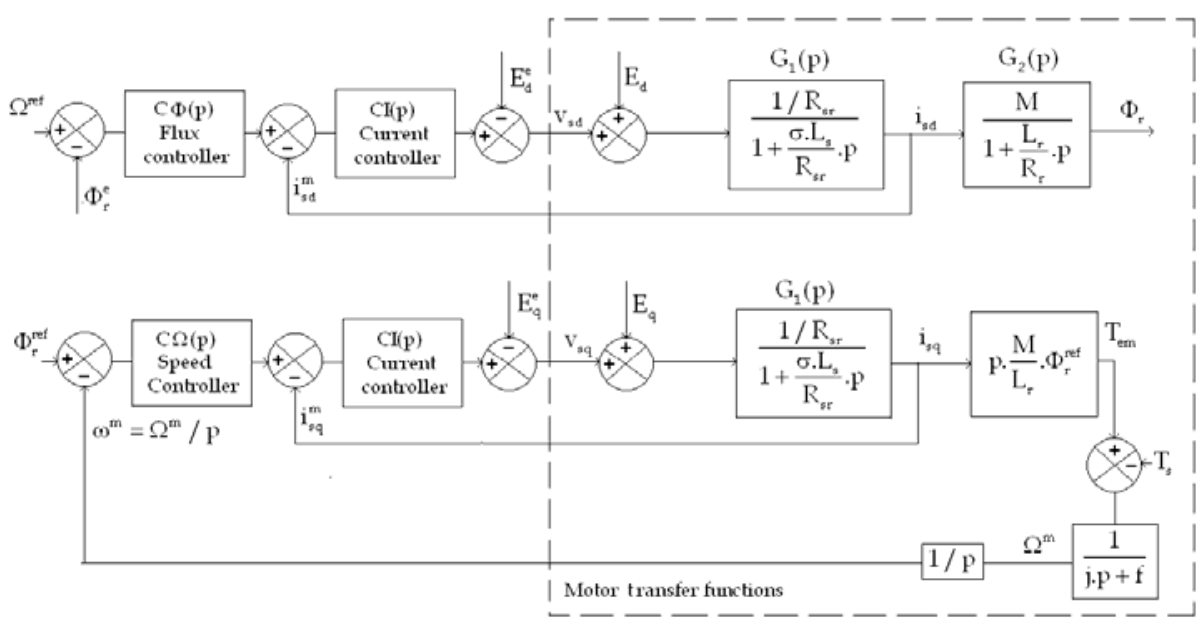

Fig. 16. FOC law scheme
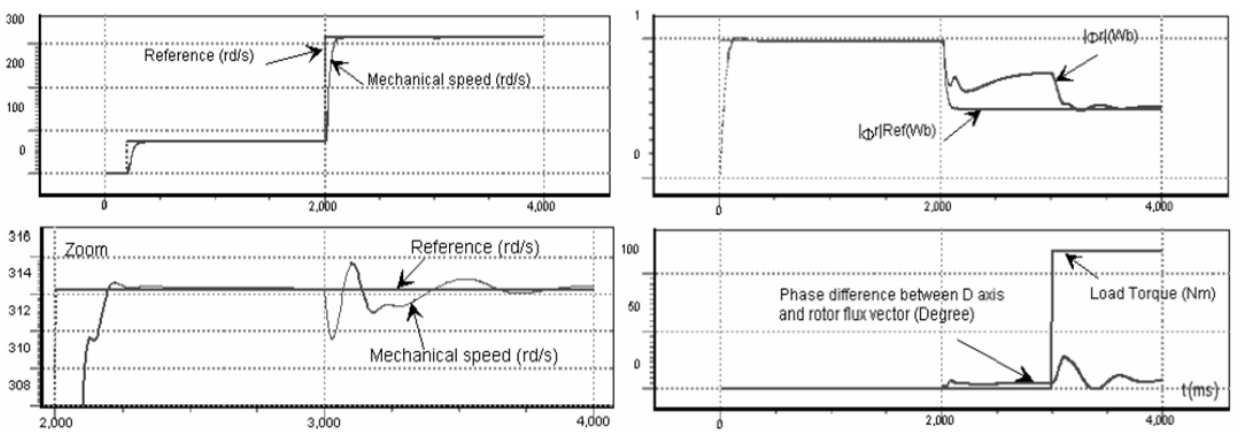

Fig. 17. Simulation results of the dynamic behavior of the induction motor modeled by the saturated two-phase model, and controlled by the classical FOC law

cyclic inductances values of the motor become different from the cyclic inductances values introduced in the controllers.

In the next paragraph, the classical FOC law is developed in order to take into account the variation of the saturation level. The new control law is called the saturated FOC law.

\subsection{New saturated FOC law}

To simplify the study, stator and rotor leakage inductances $\left(\mathrm{L}_{\mathrm{sf}}\right.$ and $\left.\mathrm{L}_{\mathrm{rf}}\right)$, are supposed to be constant. Only the mutual cyclic inductance $M$ is considered to be variable with the modulus of magnetizing current vector, where $L_{s}=M+L_{s f}$ and $L_{r}=M+L_{r f}$.

From expression (13), The derivative of the stator flux vector is:

$$
\frac{d \Phi_{s}}{d t}=\sigma \cdot L_{s} \cdot \frac{d \bar{I}_{s}}{d t}+\frac{M}{L_{r}} \cdot \frac{d \Phi_{r}}{d t}+\overline{I_{s}} \cdot \frac{d\left(\sigma L_{s}\right)}{d t}+\Phi_{r} \cdot \frac{d\left(\frac{M}{L_{r}}\right)}{d t}=\sigma \cdot L_{s} \cdot \frac{d \bar{I}_{s}}{d t}+\frac{M}{L_{r}} \cdot \frac{d \Phi_{r}}{d t}+\bar{I}_{s} \cdot \frac{d M}{d t} \cdot\left(\frac{L_{r f}^{2}}{L_{r}^{2}}\right)+\Phi_{r} \cdot \frac{d M}{d t} \cdot \frac{L_{r f}}{L_{r}^{2}}
$$


Finally the expression of the stator flux vector derivative is:

$$
\frac{\mathrm{d} \overline{\Phi_{\mathrm{s}}}}{\mathrm{dt}}=\sigma \cdot \mathrm{L}_{\mathrm{s}} \cdot \frac{\mathrm{d} \overline{\mathrm{I}}_{\mathrm{s}}}{\mathrm{dt}}+\frac{\mathrm{M}}{\mathrm{L}_{\mathrm{r}}} \cdot \frac{\mathrm{d} \Phi_{\mathrm{r}}}{\mathrm{dt}}+\left(\overline{\mathrm{I}_{\mathrm{s}}} \cdot \mathrm{L}_{\mathrm{rf}}+\Phi_{\mathrm{r}}\right) \frac{\mathrm{L}_{\mathrm{rf}}}{\mathrm{L}_{\mathrm{r}}^{2}} \cdot \frac{\mathrm{dM}}{\mathrm{dt}}
$$

The stator voltage vector is then modified to:

$$
\overline{\mathrm{V}_{\mathrm{s}}}=\mathrm{R}_{\mathrm{s}} \cdot \overline{\mathrm{I}}_{\mathrm{s}}+\sigma \cdot \mathrm{L}_{\mathrm{s}} \cdot \frac{\mathrm{d} \overline{\mathrm{I}}_{\mathrm{s}}}{\mathrm{dt}}+\frac{\mathrm{M}}{\mathrm{L}_{\mathrm{r}}} \cdot \frac{\mathrm{d} \Phi_{\mathrm{r}}}{\mathrm{dt}}+\left(\overline{\mathrm{I}_{\mathrm{s}}} \cdot \mathrm{L}_{\mathrm{rf}}+\Phi_{\mathrm{r}}\right) \frac{\mathrm{L}_{\mathrm{rf}}}{\mathrm{L}_{\mathrm{r}}^{2}} \cdot \frac{\mathrm{dM}}{\mathrm{dt}}+\mathrm{j} \cdot \omega_{\mathrm{s}} \cdot \overline{\Phi_{\mathrm{s}}}
$$

As previous, the resistance $R_{s r}$ can be introduced. The stator voltages on the $D$ and $Q$ axes are:

$$
\begin{gathered}
\mathrm{v}_{\mathrm{sd}}=\mathrm{R}_{\mathrm{sr}} \cdot \mathrm{i}_{\mathrm{sd}}+\sigma \cdot \mathrm{L}_{\mathrm{s}} \cdot \frac{\mathrm{di}}{\mathrm{dt}}-\mathrm{R}_{\mathrm{r}} \cdot \frac{\mathrm{M}}{\mathrm{L}_{\mathrm{r}}^{2}} \cdot\left|\overline{\Phi_{\mathrm{r}}}\right|-\sigma \cdot \mathrm{L}_{\mathrm{s}} \cdot \omega_{\mathrm{s}} \cdot \mathrm{i}_{\mathrm{sq}}+\left(\mathrm{i}_{\mathrm{sd}} \cdot \mathrm{L}_{\mathrm{rf}}+\mid \overline{\Phi_{\mathrm{r}}}\right) \frac{\mathrm{L}_{\mathrm{rf}}}{\mathrm{L}_{\mathrm{r}}^{2}} \cdot \frac{\mathrm{dM}}{\mathrm{dt}} \\
=\mathrm{R}_{\mathrm{sr}} \mathrm{i}_{\mathrm{sd}}+\sigma \cdot \mathrm{L}_{\mathrm{s}} \cdot \frac{\mathrm{di}_{\mathrm{sd}}}{\mathrm{dt}}+\mathrm{E}_{\mathrm{d}} \\
\mathrm{v}_{\mathrm{sq}}=\mathrm{R}_{\mathrm{sr}} \cdot \mathrm{i}_{\mathrm{sq}}+\sigma \cdot \mathrm{L}_{\mathrm{s}} \cdot \frac{\mathrm{di} \mathrm{sq}_{\mathrm{sq}}}{\mathrm{dt}}+\omega \cdot \frac{\mathrm{M}}{\mathrm{L}_{\mathrm{r}}} \cdot\left|\Phi_{\mathrm{r}}\right|+\mathrm{i}_{\mathrm{sq}} \cdot \frac{\mathrm{L}_{\mathrm{rf}}^{2}}{\mathrm{~L}_{\mathrm{r}}^{2}} \cdot \frac{\mathrm{dM}}{\mathrm{dt}}+\sigma \cdot \mathrm{L}_{\mathrm{s}} \cdot \omega_{\mathrm{s}} \cdot \mathrm{i}_{\mathrm{sd}}=\mathrm{R}_{\mathrm{sr}} \cdot \mathrm{i}_{\mathrm{sq}}+\sigma \cdot \mathrm{L}_{\mathrm{s}} \cdot \frac{\mathrm{di}}{\mathrm{dt}}+\mathrm{E}_{\mathrm{q}}
\end{gathered}
$$

where $E_{d}$ and $E_{q}$ are electrical forces and equal to:

$$
\begin{gathered}
\mathrm{E}_{\mathrm{d}}=\mathrm{R}_{\mathrm{r}} \cdot \frac{\mathrm{M}}{\mathrm{L}_{\mathrm{r}}^{2}} \cdot\left|\overline{\Phi_{\mathrm{r}}}\right|+\sigma \cdot \mathrm{L}_{\mathrm{s}} \cdot \omega_{\mathrm{s}} \cdot \mathrm{i}_{\mathrm{sq}}-\left(\mathrm{i}_{\mathrm{sd}} \cdot \mathrm{L}_{\mathrm{rf}}+\mid \overline{\Phi_{\mathrm{r}}}\right) \cdot \frac{\mathrm{L}_{\mathrm{rf}}}{\mathrm{L}_{\mathrm{r}}^{2}} \cdot \frac{\mathrm{dM}}{\mathrm{dt}}, \\
\mathrm{E}_{\mathrm{q}}=-\omega \cdot \frac{\mathrm{M}}{\mathrm{L}_{\mathrm{r}}} \cdot\left|\overline{\Phi_{\mathrm{r}}}\right|-\sigma \cdot \mathrm{L}_{\mathrm{s}} \cdot \omega_{\mathrm{s}} \cdot \mathrm{i}_{\mathrm{sd}}-\mathrm{i}_{\mathrm{sq}} \cdot \frac{\mathrm{L}_{\mathrm{rf}}^{2}}{\mathrm{~L}_{\mathrm{r}}^{2}} \cdot \frac{\mathrm{dM}}{\mathrm{dt}} .
\end{gathered}
$$

The obtained transfer functions are approximately the same as in the linear case. The main difference is that the parameters of these transfer functions are time variant. Terms containing $\frac{d M}{d t}$ appear in the expressions of $E_{d}$ and $E_{q}$. Anyhow, this term can be neglected since $\frac{L_{r}}{R_{r}}$ is bigger than $10 \frac{\sigma L_{s}}{R_{s}}$ for induction machines, so the expressions of $E_{d}$ and $E_{q}$ become:

$$
\mathrm{E}_{\mathrm{d}} \approx \mathrm{R}_{\mathrm{r}} \cdot \frac{\mathrm{M}}{\mathrm{L}_{\mathrm{r}}^{2}} \cdot\left|\overline{\Phi_{\mathrm{r}}}\right|+\sigma \cdot \mathrm{L}_{\mathrm{s}} \cdot \omega_{\mathrm{s}} \cdot \mathrm{i}_{\mathrm{sq}}, \mathrm{E}_{\mathrm{q}} \approx-\omega \cdot \frac{\mathrm{M}}{\mathrm{L}_{\mathrm{r}}} \cdot\left|\overline{\Phi_{\mathrm{r}}}\right|-\sigma \cdot \mathrm{L}_{\mathrm{s}} \cdot \omega_{\mathrm{s}} \cdot \mathrm{i}_{\mathrm{sd}} \cdot
$$

The idea of the saturated FOC is to tune the coefficients of the controllers according to the value of $\left|\overline{\mathrm{I}_{\mathrm{m}}}\right|$. At each sampling period $\mid \underline{\mathrm{I}_{\mathrm{m}} \mid}$ is calculated, and the corresponding cyclic inductances are found from look up tables to update the controller's coefficients.

The expression of $\left|\overline{I_{m}}\right|$ is $\left|\overline{I_{m}}\right|=\sqrt{\left(i_{s d}+i_{r d}\right)^{2}+\left(i_{s q}+i_{r q}\right)^{2}} \cdot i_{s d}$ and $i_{s q}$ can be measured at each sampling period. $i_{r d}$ can be calculated from the first rotor equation (15), and $i_{r q}$ from the equation (17) using a non-linear resolution method as the substitution method. 
Fig. 18 shows the strategy of the new FOC law. The blocks with dashed lines are the blocks necessary for calculating the modulus of magnetizing current vector. At each sampling period the controller's coefficients are updated according to the new values of the cyclic inductances.

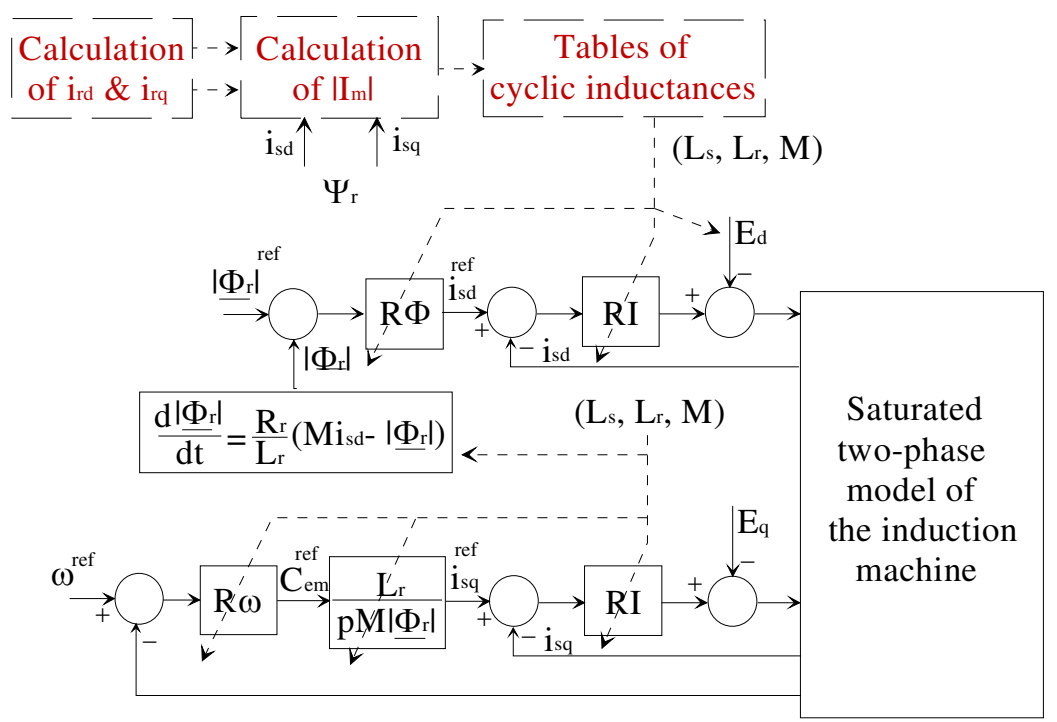

Fig. 18. Saturated FOC law

Fig. 19 presents simulation results of the dynamic response of the $45 \mathrm{KW}$ induction motor controlled by the new saturated FOC control. This simulation is done for the same inputs of figure 5 . It is clear that the performance of the machine is clearly improved.
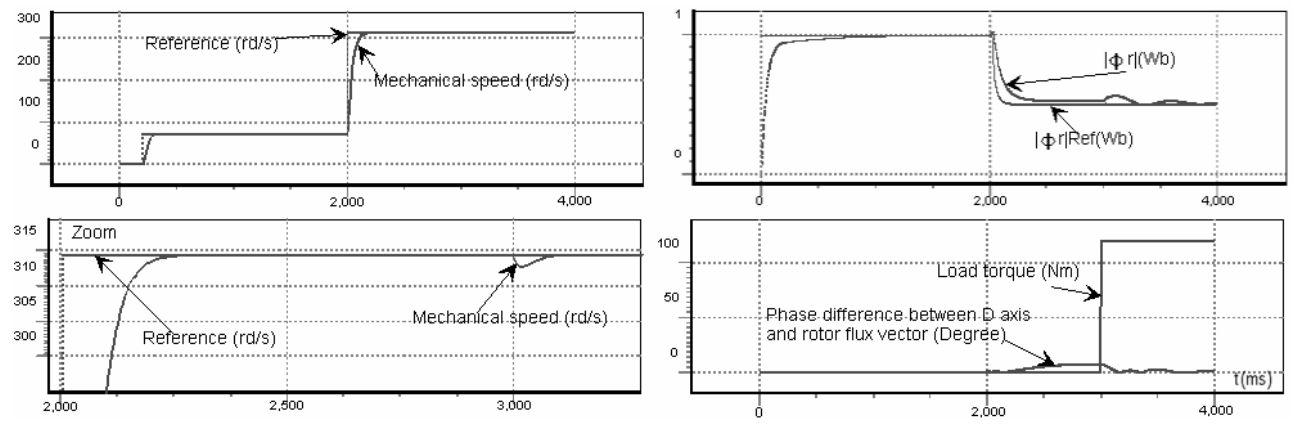

Fig. 20. Simulation results with saturated FOC

\section{Stator flux estimation improvement during the flux weakening phase for the Direct Torque Control Law}

Thirteen years after developing the FOC law by F. Blaschke in 1971 (Blaschke, F. 1972), I. Takahashi and M. Depenbrock presented a new technique for the induction motor torque 
control called Direct Torque Control (DTC), (Noguchi, T. \& Takahashi, I. 1984), Depenbrock, M. \& Steimel A. 1990). DTC is based on applying the appropriate voltage space vector in order to achieve the desired flux and torque variations.

DTC permits to have very fast dynamics without any intermediate current control loops.

The DTC is based on the fact that the variations of the stator flux vector are directly controlled by the stator voltage vector for high speed:

$$
\overline{\mathrm{V}_{\mathrm{s}}}=\mathrm{R}_{\mathrm{s}} \cdot \overline{\mathrm{I}}_{\mathrm{s}}+\frac{\mathrm{d} \overline{\Phi_{\mathrm{s}}}}{\mathrm{dt}} \approx \frac{\mathrm{d} \overline{\Phi_{\mathrm{s}}}}{\mathrm{dt}}
$$

\subsection{Direct Torque Control Law for an induction machine with a voltage source inverter drive}

A small variation of the stator flux vector is in fact the product of the stator voltage vector and the sampling period $\Delta \mathrm{T}$ :

$$
\Delta \overline{\Phi_{\mathrm{s}}}=\overline{\mathrm{V}_{\mathrm{s}}} \cdot \Delta \mathrm{T}
$$

Usually, the motor is driven by a voltage source inverter. The stator voltage vector for such an inverted has only 8 positions, Fig. 21. From Fig. 21 If the stator flux vector is in sector i, then its magnitude is increased when applying $\overline{V_{i}}, \overline{V_{i+1}}$ or $\overline{V_{i-1}}$. To decrease $\overline{\Phi_{s}}$, the vector $\overline{\mathrm{V}_{\mathrm{i}+2}}, \overline{\mathrm{V}_{\mathrm{i}-2}}$ or $\overline{\mathrm{V}_{\mathrm{i}+3}}$ can be applied.
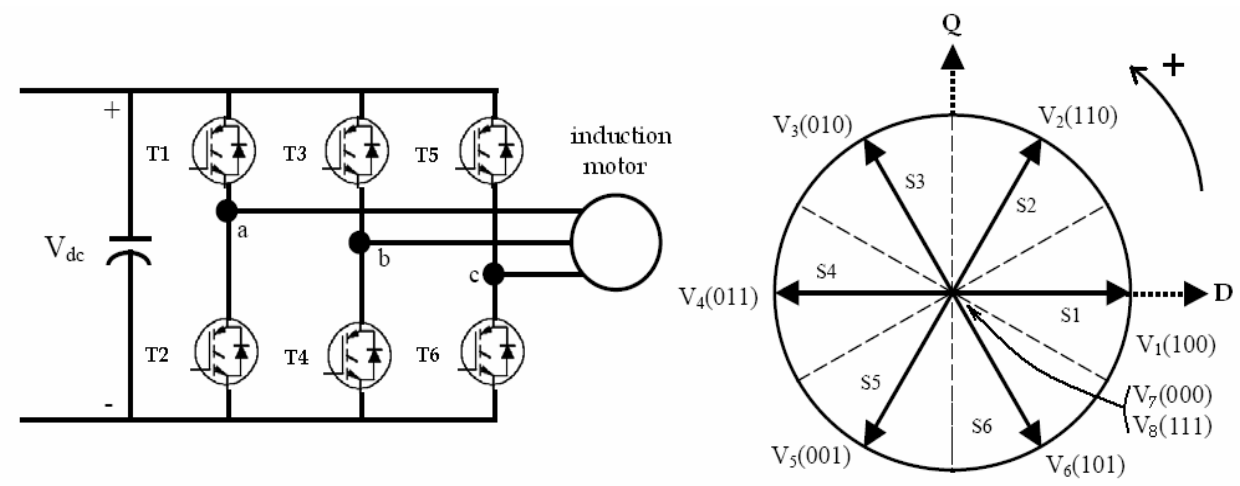

Fig. 21. Stator Voltage space vector for a voltage source inverter

In order to search what does the stator voltage space vector act on the motor torque, its expression can be rewritten starting from equation (6) and taking into account the fluxcurrent relationships as follows:

$$
\begin{gathered}
\mathrm{T}_{\mathrm{em}}=\mathrm{p} \cdot \overline{\Phi_{\mathrm{s}}} \wedge \overline{\mathrm{I}_{\mathrm{s}}} \\
\mathrm{T}_{\mathrm{em}}=\mathrm{p} \cdot \frac{\mathrm{M}}{\mathrm{Ls} \cdot \operatorname{Lr}-\mathrm{M} 2} \cdot \overline{\Phi_{\mathrm{s}}} \wedge \overline{\Phi_{\mathrm{r}}}=\mathrm{p} \cdot \frac{\mathrm{M}}{\mathrm{Ls} \cdot \operatorname{Lr}-\mathrm{M} 2} \cdot\left|\overline{\Phi_{\mathrm{s}}}\right| \cdot\left|\overline{\Phi_{\mathrm{r}}}\right| \cdot \sin \theta_{\mathrm{sr}}
\end{gathered}
$$

where $\theta_{\mathrm{sr}}$ is the angle difference between $\overline{\Phi_{\mathrm{s}}}$ and $\overline{\Phi_{\mathrm{r}}}$. 
It is important to mention that the rotor flux vector time constant is bigger than the time constant of the stator flux vector. This can be demonstrated by writing the transfer function from the stator flux vector to the rotor flux vector. For a two-phase reference related to the rotor: $\psi=p \theta$, the rotor electric equation becomes: $\overline{0}=\mathrm{R}_{\mathrm{r}} \cdot \overline{\mathrm{I}}_{\mathrm{r}}+\frac{\mathrm{d} \overline{\Phi_{\mathrm{r}}}}{\mathrm{dt}}$. From the flux-current relationships: $\overline{\mathrm{I}_{\mathrm{r}}}=\frac{\overline{\Phi_{\mathrm{r}}}}{\sigma \cdot \mathrm{L}_{\mathrm{r}}}-\frac{\mathrm{M}}{\sigma \cdot \mathrm{L}_{\mathrm{s}} \cdot \mathrm{L}_{\mathrm{r}}} \cdot \overline{\Phi_{\mathrm{s}}}$. By substituting the expression of $\overline{\mathrm{I}_{\mathrm{r}}}$ in the rotor electric equation, the following transfer function is obtained:

$$
\frac{\overline{\Phi_{\mathrm{r}}}}{\overline{\Phi_{\mathrm{s}}}}=\frac{\mathrm{M} / \mathrm{L}_{\mathrm{r}}}{1+\sigma \cdot \tau_{\mathrm{r}} \cdot \mathrm{p}}
$$

where $\tau_{\mathrm{r}}=\mathrm{R}_{\mathrm{r}} / \mathrm{L}_{\mathrm{r}}$ is the rotor time constant. From equation (32), it is clear that the stator flux vector changes slowly compared to the stator flux vector.

Going back to the expression of the motor torque, equation (31), if the stator flux vector modulus is maintained constant, then the motor torque can be rapidly changed and controlled by changing the angle $\theta_{\mathrm{sr}}$. Thus the tangential component of $\Delta \overline{\Phi_{\mathrm{s}}}=\overline{\mathrm{V}_{\mathrm{s}}} \cdot \Delta \mathrm{T}$ is for controlling the torque, and its radial component is for controlling $\left|\overline{\Phi_{s}}\right|$.

For a stator flux vector existing in sector $i$, the following stator voltage vector can is applied in order to have the desired variations of the stator flux vector modulus and the motor torque.

\begin{tabular}{|c|c|c|}
\hline$\overline{\mathrm{V}_{\mathrm{s}}}$ & Increase & Decrease \\
\hline$\left|\overline{\Phi_{\mathrm{s}}}\right|$ & $\overline{\mathrm{V}_{\mathrm{i}}}, \overline{\mathrm{V}_{\mathrm{i}+1}}$ or $\overline{\mathrm{V}_{\mathrm{i}-1}}$ & $\overline{\mathrm{V}_{\mathrm{i}+2}}, \overline{\mathrm{V}_{\mathrm{i}-2}}$ or $\overline{\mathrm{V}_{\mathrm{i}+3}}$ \\
\hline $\mathrm{T}_{\mathrm{em}}$ & $\overline{\mathrm{V}_{\mathrm{i}+1}}$ or $\overline{\mathrm{V}_{\mathrm{i}+2}}$ & $\overline{\mathrm{V}_{\mathrm{i}-1}}$ or $\overline{\mathrm{V}_{\mathrm{i}-2}}$ \\
\hline
\end{tabular}

Table 1. Stator voltage vector for the desired variations of $\left|\overline{\Phi_{s}}\right|$ and $T_{e m}$

The vectors $\bar{V}_{\mathrm{i}}$ and $\overline{\mathrm{V}_{\mathrm{i}+3}}$ are not considered for controlling the torque because they increase the torque for the positive 30 degree half sector, and decrease it for the negative 30 degree half sector. They can be used if 12 sectors are considered for dividing the total locus.

By analyzing Table 1, it is possible to do a decoupled control of $\left|\overline{\Phi_{s}}\right|$ and $T_{\text {em. }}$. For all the six sectors, Table 2 shows the good stator voltage vector that gives the desired variations of $\left|\overline{\Phi_{\mathrm{s}}}\right|$ and $\mathrm{T}_{\mathrm{em}}$.

Fig. 22 shows the scheme of the DTC.

There are two different loops for controlling the stator flux vector modulus and the motor torque. The reference values of $\left|\overline{\Phi_{s}}\right|$ and $T_{\mathrm{em}}$ are compared with the estimated values. The resulting errors are fed into the two-level and three-level hysteresis comparators respectively. The outputs of the hysteresis comparators and the position of the stator flux vector are used as inputs for the look up table (selection table of Table 2). 


\begin{tabular}{|c|c|c|c|c|c|c|c|}
\hline \multirow{2}{*}{$\left|\overline{\Phi_{\mathrm{s}}}\right|$} & $\mathrm{T}_{\mathrm{em}}$ & $\mathrm{S} 1$ & $\mathrm{~S} 2$ & $\mathrm{~S} 3$ & $\mathrm{~S} 4$ & $\mathrm{~S} 5$ & $\mathrm{~S} 6$ \\
\hline \multirow{3}{*}{$\mathrm{FI}$} & $\mathrm{TI}$ & $\mathrm{V}_{2}$ & $\mathrm{~V}_{3}$ & $\mathrm{~V}_{4}$ & $\mathrm{~V}_{5}$ & $\mathrm{~V}_{6}$ & $\mathrm{~V}_{1}$ \\
\cline { 2 - 8 } & $=$ & $\mathrm{V}_{0}$ & $\mathrm{~V}_{7}$ & $\mathrm{~V}_{0}$ & $\mathrm{~V}_{7}$ & $\mathrm{~V}_{0}$ & $\mathrm{~V}_{7}$ \\
\cline { 2 - 8 } & $\mathrm{TD}$ & $\mathrm{V}_{6}$ & $\mathrm{~V}_{1}$ & $\mathrm{~V}_{2}$ & $\mathrm{~V}_{3}$ & $\mathrm{~V}_{4}$ & $\mathrm{~V}_{5}$ \\
\hline \multirow{3}{*}{$\mathrm{FD}$} & $\mathrm{TI}$ & $\mathrm{V}_{3}$ & $\mathrm{~V}_{4}$ & $\mathrm{~V}_{5}$ & $\mathrm{~V}_{6}$ & $\mathrm{~V}_{1}$ & $\mathrm{~V}_{2}$ \\
\cline { 2 - 8 } & $=$ & $\mathrm{V}_{7}$ & $\mathrm{~V}_{0}$ & $\mathrm{~V}_{7}$ & $\mathrm{~V}_{0}$ & $\mathrm{~V}_{7}$ & $\mathrm{~V}_{0}$ \\
\cline { 2 - 8 } & $\mathrm{TD}$ & $\mathrm{V}_{5}$ & $\mathrm{~V}_{6}$ & $\mathrm{~V}_{1}$ & $\mathrm{~V}_{2}$ & $\mathrm{~V}_{3}$ & $\mathrm{~V}_{4}$ \\
\hline
\end{tabular}

Table 2. Stator voltage vector for the desired variations of $\left|\overline{\Phi_{s}}\right|$ and $T_{e m}$ in all sectors

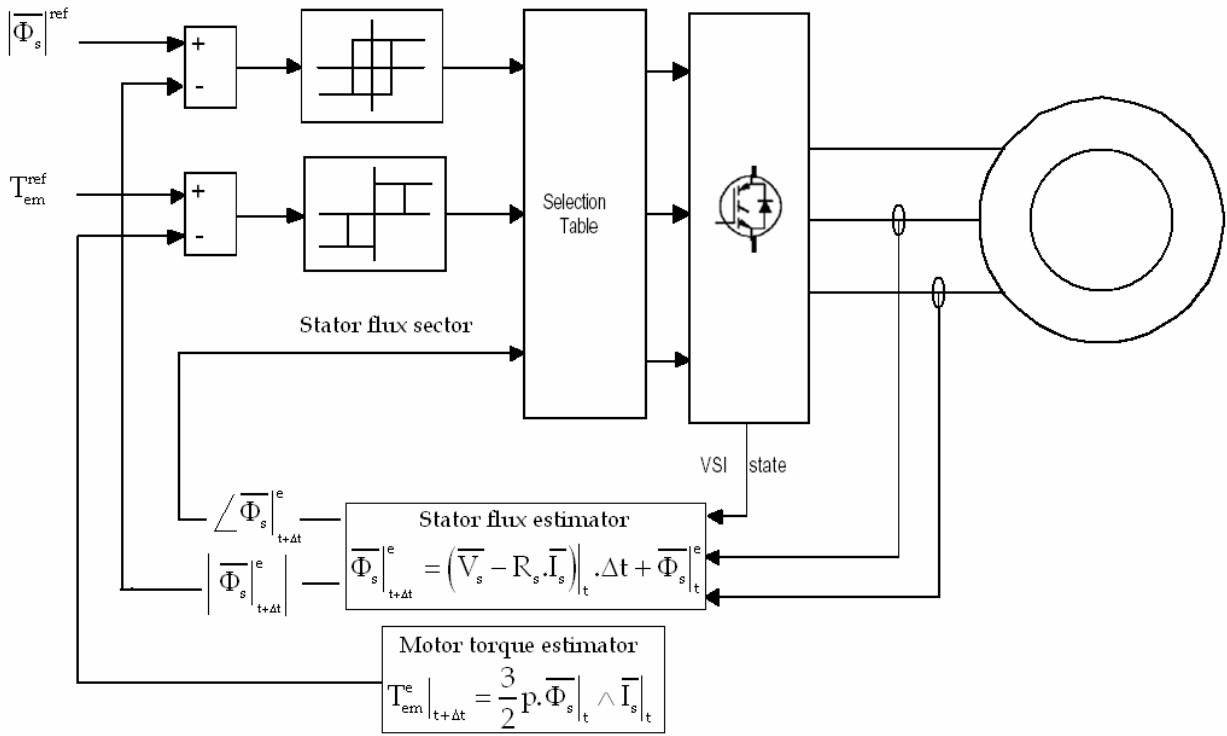

Fig. 22. Scheme of the DTC law

Usually, the estimation of the stator flux vector is done using the stator electric equation:

$$
\left.\overline{\Phi_{s}}\right|_{t+\Delta t} ^{e}=\left.\left(\overline{V_{s}}-R_{s} \cdot \overline{I_{s}}\right)\right|_{t} \cdot \Delta t+\left.\overline{\Phi_{s}}\right|_{t} ^{e}
$$

The accuracy of this flux estimator is highly dependent on the value of the stator winding resistor, which varies with the motor temperature.

This chapter proposes a new estimation technique that uses the rotor electric equation. It shows that it is less sensitive to the variation of the rotor resistor, but more sensitive to the variation of the saturation level. To overcome this problem, an adaptive estimator is proposed, based on a previous saturation phenomenon study. 


\subsection{Direct Torque Control Law for an induction machine for a fixed chopping frequency voltage source inverter}

It is possible to develop the expression of a continuous optimal stator voltage vector that gives the desired variations of $\left|\overline{\Phi_{s}}\right|$ and $T_{e m}$ (C.A, Martins.; T.A, Meynard.; X, Roboam. \& A.S, Carvalho2, 1999). The control voltages $\mathrm{v}_{\mathrm{sd}}^{\mathrm{opt}}$ and $\mathrm{v}_{\mathrm{sq}}^{\mathrm{opt}}$ that give the desired $\Delta \mathrm{T}_{\mathrm{em}}^{\mathrm{Des}} / \Delta \mathrm{t}$ and $\Delta\left|\overline{\Phi_{\mathrm{s}}}\right|^{\text {Des }} / \Delta \mathrm{t}$ are searched.

The expression of the motor torque derivative is:

$$
\frac{\mathrm{dT}_{\mathrm{em}}}{\mathrm{dt}}=\mathrm{p}\left(\frac{\mathrm{d} \Phi_{\mathrm{sd}}}{\mathrm{dt}} \cdot \mathrm{i}_{\mathrm{sq}}+\Phi_{\mathrm{sd}} \cdot \frac{\mathrm{di}_{\mathrm{sq}}}{\mathrm{dt}}-\frac{\mathrm{d} \Phi_{\mathrm{sq}}}{\mathrm{dt}} \cdot \mathrm{i}_{\mathrm{sd}}-\Phi_{\mathrm{sq}} \cdot \frac{\mathrm{di}_{\mathrm{sd}}}{\mathrm{dt}}\right)
$$

The expressions of $\frac{\mathrm{d} \Phi_{\mathrm{sd}}}{\mathrm{dt}}$ and $\frac{\mathrm{d} \Phi_{\mathrm{sq}}}{\mathrm{dt}}$ can be found from the stator electric equations in the fixed reference:

$$
\begin{aligned}
& \frac{\mathrm{d} \Phi_{\mathrm{sd}}}{\mathrm{dt}}=\mathrm{v}_{\mathrm{sd}}-\mathrm{R}_{\mathrm{s}} \cdot \mathrm{i}_{\mathrm{sd}} \\
& \frac{\mathrm{d} \Phi_{\mathrm{sq}}}{\mathrm{dt}}=\mathrm{v}_{\mathrm{sq}}-\mathrm{R}_{\mathrm{s}} \cdot \mathrm{i}_{\mathrm{sq}}
\end{aligned}
$$

By writing the expressions of $i_{\text {sd }}$ and $i_{\text {sq }}$ from the flux-current relationships, the derivatives of these currents versus time are:

$$
\begin{aligned}
\frac{\mathrm{di}_{\mathrm{sd}}}{\mathrm{dt}} & =\frac{1}{\sigma \cdot \mathrm{L}_{\mathrm{s}}} \cdot\left(\frac{\mathrm{d} \Phi_{\mathrm{sd}}}{\mathrm{dt}}-\frac{\mathrm{M}}{\mathrm{Lr}} \cdot \frac{\mathrm{d} \Phi_{\mathrm{rd}}}{\mathrm{dt}}\right) \\
\frac{\mathrm{di}_{\mathrm{sq}}}{\mathrm{dt}} & =\frac{1}{\sigma \cdot \mathrm{L}_{\mathrm{s}}} \cdot\left(\frac{\mathrm{d} \Phi_{\mathrm{sq}}}{\mathrm{dt}}-\frac{\mathrm{M}}{\mathrm{Lr}} \cdot \frac{\mathrm{d} \Phi_{\mathrm{rq}}}{\mathrm{dt}}\right)
\end{aligned}
$$

The rotor electric equations give the expressions of the rotor fluxes derivatives versus time:

$$
\begin{aligned}
& \frac{\mathrm{d} \Phi_{\mathrm{rd}}}{\mathrm{dt}}=-\frac{\mathrm{d}(\mathrm{p} \theta)}{\mathrm{dt}} \cdot \Phi_{\mathrm{rq}}-\mathrm{R}_{\mathrm{r}} \cdot \mathrm{i}_{\mathrm{rd}}=-\frac{\mathrm{d}(\mathrm{p} \theta)}{\mathrm{dt}} \cdot \Phi_{\mathrm{rq}}-\frac{\mathrm{R}_{\mathrm{r}}}{\mathrm{M}} \cdot\left(\Phi_{\mathrm{sd}}-\mathrm{L}_{\mathrm{s}} \cdot \mathrm{i}_{\mathrm{sd}}\right) \\
& \frac{\mathrm{d} \Phi_{\mathrm{rq}}}{\mathrm{dt}}=\frac{\mathrm{d}(\mathrm{p} \theta)}{\mathrm{dt}} \cdot \Phi_{\mathrm{rd}}-\mathrm{R}_{\mathrm{r}} \cdot \mathrm{i}_{\mathrm{rq}}=\frac{\mathrm{d}(\mathrm{p} \theta)}{\mathrm{dt}} \cdot \Phi_{\mathrm{rd}}-\frac{\mathrm{R}_{\mathrm{r}}}{\mathrm{M}} \cdot\left(\Phi_{\mathrm{sq}}-\mathrm{L}_{\mathrm{s}} \cdot \mathrm{i}_{\mathrm{sq}}\right)
\end{aligned}
$$

The final expressions of the stator fluxes derivatives can be obtained by substituting $\Phi_{\mathrm{rd}}$ and $\Phi_{\mathrm{rq}}$ by their expressions using stator variables:

$$
\begin{aligned}
& \frac{\mathrm{d} \Phi_{\mathrm{rd}}}{\mathrm{dt}}=-\frac{\mathrm{d}(\mathrm{p} \theta)}{\mathrm{dt}} \cdot \Phi_{\mathrm{rq}}-\mathrm{R}_{\mathrm{r}} \cdot \mathrm{i}_{\mathrm{rd}}=-\frac{\mathrm{d}(\mathrm{p} \theta)}{\mathrm{dt}} \cdot \frac{\mathrm{L}_{\mathrm{r}}}{\mathrm{M}}\left(\Phi_{\mathrm{sq}}-\sigma \cdot \mathrm{L}_{\mathrm{s}} \cdot \mathrm{i}_{\mathrm{sq}}\right)-\frac{\mathrm{R}_{\mathrm{r}}}{\mathrm{M}} \cdot\left(\Phi_{\mathrm{sd}}-\mathrm{L}_{\mathrm{s}} \cdot \mathrm{i}_{\mathrm{sd}}\right) \\
& \frac{\mathrm{d} \Phi_{\mathrm{rq}}}{\mathrm{dt}}=\frac{\mathrm{d}(\mathrm{p} \theta)}{\mathrm{dt}} \cdot \Phi_{\mathrm{rd}}-\mathrm{R}_{\mathrm{r}} \cdot \mathrm{i}_{\mathrm{rq}}=\frac{\mathrm{d}(\mathrm{p} \theta)}{\mathrm{dt}} \cdot \frac{\mathrm{L}_{\mathrm{r}}}{\mathrm{M}}\left(\Phi_{\mathrm{sd}}-\sigma \cdot \mathrm{L}_{\mathrm{s}} \cdot \mathrm{i}_{\mathrm{sd}}\right)-\frac{\mathrm{R}_{\mathrm{r}}}{\mathrm{M}} \cdot\left(\Phi_{\mathrm{sq}}-\mathrm{L}_{\mathrm{s}} \cdot \mathrm{i}_{\mathrm{sq}}\right)
\end{aligned}
$$

By replacing (38) in (36), the stator currents derivatives become: 


$$
\begin{aligned}
& \frac{\mathrm{di}_{\mathrm{sd}}}{\mathrm{dt}}=\frac{1}{\sigma \cdot \mathrm{L}_{\mathrm{s}}} \cdot\left(\frac{\mathrm{d} \Phi_{\mathrm{sd}}}{\mathrm{dt}}-\frac{\mathrm{M}}{\mathrm{Lr}} \cdot\left(-\frac{\mathrm{d}(\mathrm{p} \theta)}{\mathrm{dt}} \cdot \frac{\mathrm{L}_{\mathrm{r}}}{\mathrm{M}}\left(\Phi_{\mathrm{sq}}-\sigma \cdot \mathrm{L}_{\mathrm{s}} \cdot \mathrm{i}_{\mathrm{sq}}\right)-\frac{\mathrm{R}_{\mathrm{r}}}{\mathrm{M}} \cdot\left(\Phi_{\mathrm{sd}}-\mathrm{L}_{\mathrm{s}} \cdot \mathrm{i}_{\mathrm{sd}}\right)\right)\right) \\
& \frac{\mathrm{di}_{\mathrm{sq}}}{\mathrm{dt}}=\frac{1}{\sigma \cdot \mathrm{L}_{\mathrm{s}}} \cdot\left(\frac{\mathrm{d} \Phi_{\mathrm{sq}}}{\mathrm{dt}}-\frac{\mathrm{M}}{\mathrm{Lr}} \cdot\left(\frac{\mathrm{d}(\mathrm{p} \theta)}{\mathrm{dt}} \cdot \frac{\mathrm{L}_{\mathrm{r}}}{\mathrm{M}}\left(\Phi_{\mathrm{sd}}-\sigma \cdot \mathrm{L}_{\mathrm{s}} \cdot \mathrm{i}_{\mathrm{sd}}\right)-\frac{\mathrm{R}_{\mathrm{r}}}{\mathrm{M}} \cdot\left(\Phi_{\mathrm{sq}}-\mathrm{L}_{\mathrm{s}} \mathrm{i}_{\mathrm{sq}}\right)\right)\right)
\end{aligned}
$$

The motor torque derivative is finally obtained as a function of stator voltage, stator current and stator flux components.

$$
\frac{\mathrm{dT}_{\mathrm{em}}}{\mathrm{dt}}=\mathrm{p}\left(\mathrm{v}_{\mathrm{sd}} \cdot \mathrm{K}_{\mathrm{sq}}-\mathrm{v}_{\mathrm{sq}} \cdot \mathrm{K}_{\mathrm{sd}}+\mathrm{K}_{1}\right)
$$

with

$$
\begin{aligned}
\mathrm{K}_{\mathrm{sd}}=\mathrm{i}_{\mathrm{sd}}-\frac{\Phi_{\mathrm{sd}}}{\sigma \cdot \mathrm{L}_{\mathrm{s}}}, \mathrm{K}_{\mathrm{sq}}=\mathrm{i}_{\mathrm{sq}}-\frac{\Phi_{\mathrm{sq}}}{\sigma \cdot \mathrm{L}_{\mathrm{s}}}, \mathrm{R}_{\mathrm{s}}^{\prime}=\mathrm{R}_{\mathrm{s}}+\frac{\mathrm{L}_{\mathrm{s}}}{\mathrm{L}_{\mathrm{r}}} \cdot \mathrm{R}_{\mathrm{r}},\left|\overline{\Phi_{\mathrm{s}}}\right|=\sqrt{\frac{2}{3}} \sqrt{\left(\Phi_{\mathrm{sd}}\right)^{2}+\left(\Phi_{\mathrm{sq}}\right)^{2}} \text { and } \\
\mathrm{K}_{1}=-\frac{\mathrm{R}_{\mathrm{s}}^{\prime}}{\sigma \cdot \mathrm{L}_{\mathrm{s}} \cdot \mathrm{p}} \mathrm{T}_{\mathrm{em}}-\frac{3 \cdot \mathrm{p} \cdot \frac{\mathrm{d} \theta}{\mathrm{dt}}}{2 \cdot \sigma \cdot \mathrm{L}_{\mathrm{s}}} \cdot\left|\overline{\Phi_{\mathrm{s}}}\right|^{2}+\mathrm{p} \cdot \frac{\mathrm{d} \theta}{\mathrm{dt}}\left(\Phi_{\mathrm{sd}} \cdot \mathrm{i}_{\mathrm{sd}}-\Phi_{\mathrm{sq}} \cdot \mathrm{i}_{\mathrm{sq}}\right)= \\
-\frac{\mathrm{R}_{\mathrm{s}}^{\prime}}{\sigma \cdot \mathrm{L}_{\mathrm{s}} \cdot \mathrm{p}} \mathrm{T}_{\mathrm{em}}-\frac{3 \cdot \mathrm{p} \cdot \frac{\mathrm{d} \theta}{\mathrm{dt}}}{2 \cdot \sigma \cdot \mathrm{L}_{\mathrm{s}}} \cdot\left|\Phi_{\mathrm{s}}\right|^{2}+\mathrm{p} \cdot \frac{\mathrm{d} \theta}{\mathrm{dt}}\left(\Phi_{\mathrm{sd}} \cdot\left(\Phi_{\mathrm{sd}}-\sigma \cdot \mathrm{L}_{\mathrm{s}} \cdot \mathrm{i}_{\mathrm{sd}}\right)-\Phi_{\mathrm{sq}} \cdot\left(\Phi_{\mathrm{sq}}-\sigma \cdot \mathrm{L}_{\mathrm{s}} \cdot \mathrm{i}_{\mathrm{sq}}\right)\right)
\end{aligned}
$$

Using the stator electric equations, the derivative of $\left|\overline{\Phi_{\mathrm{s}}}\right|=\sqrt{\frac{2}{3}} \sqrt{\left(\Phi_{\mathrm{sd}}\right)^{2}+\left(\Phi_{\mathrm{sq}}\right)^{2}}$ can be found:

$$
\frac{\mathrm{d}\left|\overline{\Phi_{\mathrm{s}}}\right|}{\mathrm{dt}}=\frac{2}{3 \cdot\left|\overline{\Phi_{\mathrm{s}}}\right|}\left(\Phi_{\mathrm{sd}} \cdot \mathrm{v}_{\mathrm{sd}}+\Phi_{\mathrm{sq}} \cdot \mathrm{v}_{\mathrm{sq}}-\mathrm{R}_{\mathrm{s}} \cdot\left(\Phi_{\mathrm{sd}} \cdot \mathrm{i}_{\mathrm{sd}}+\Phi_{\mathrm{sq}} \cdot \mathrm{i}_{\mathrm{sq}}\right)\right)
$$

Finally, the optimal control $\mathrm{v}_{\mathrm{sd}}^{\mathrm{opt}}$ and $\mathrm{v}_{\mathrm{sq}}^{\mathrm{opt}}$ are obtained by replacing the desired variations during the sampling period $\Delta \mathrm{T}_{\mathrm{em}}^{\mathrm{Des}} / \Delta \mathrm{t}$ and $\Delta\left|\bar{\Phi}_{\mathrm{s}}\right|^{\text {Des }} / \Delta \mathrm{t}$ in equations (40) and (41) instead of the derivatives $\frac{\mathrm{dT}_{\mathrm{em}}}{\mathrm{dt}}$ and $\frac{\mathrm{d}\left|\overline{\Phi_{\mathrm{s}}}\right|}{\mathrm{dt}}$.

$$
\mathrm{v}_{\mathrm{sd}}^{\mathrm{opt}}=\frac{\frac{3}{2} \cdot \Phi_{\mathrm{s}} \cdot\left(\Delta\left|\Phi_{\mathrm{s}}\right|^{\text {Des }} / \Delta \mathrm{t}\right) \cdot \mathrm{K}_{\mathrm{sd}}+\mathrm{R}_{\mathrm{s}} \cdot \mathrm{K}_{\mathrm{sd}} \cdot\left(\Phi_{\mathrm{sd}} \cdot \mathrm{i}_{\mathrm{sd}}+\Phi_{\mathrm{sq}} \cdot \mathrm{i}_{\mathrm{sq}}\right)+\Phi_{\mathrm{sq}} \cdot\left(\left(\Delta \mathrm{T}_{\mathrm{em}}^{\mathrm{Des}} / \Delta \mathrm{t}\right) / \mathrm{p}-\mathrm{K}_{1}\right)}{\Phi_{\mathrm{sd}} \cdot \mathrm{K}_{\mathrm{sd}}+\Phi_{\mathrm{sq}} \cdot \mathrm{K}_{\mathrm{sq}}}
$$

At each sampling period the stator currents are measured and the stator fluxes are estimated from the stator electric equations. Actual values of $\left|\overline{\Phi_{s}}\right|$ and $T_{\mathrm{em}}$ are then calculated. Using the reference values for the motor torque and for the modulus of the stator flux vector, the 
desired variations during a period of $\Delta t$ are calculated and used in equation (42) to find the optimal values of the control $\mathrm{v}_{\mathrm{sd}}^{\mathrm{opt}}$ and $\mathrm{v}_{\mathrm{sq}}^{\mathrm{opt}}$.

This control strategy can be implemented using a fixed chopping frequency source voltage inverter.

\subsection{Sensitivity study of the DTC stator flux estimator to the variation of the stator resistor}

The classical stator flux estimator used generally for the DTC is based on the stator electric equation written in a fixed two-phase reference: $\Psi=0, \underline{V_{s}}=R_{s} I_{s}+\frac{d \Phi_{s}}{d t}$. It is clear that this estimator is highly affected by the stator resistor variations, due to the motor temperature variations, especially for low speed applications.

The DTC for fixed chopping frequency of the voltage source inverter is implemented in A_MOS program. Fig. 23 shows simulation results of a $45(\mathrm{KW})$ induction machine controlled by the DTC law with the previous estimator. A difference of $15 \%$ between the motor stator resistor and its value implemented in the control estimator is considered.
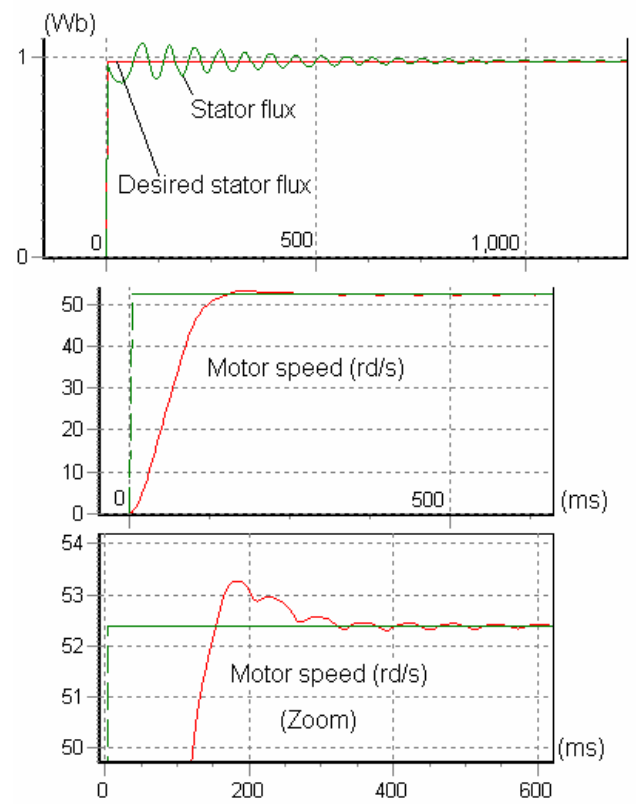

Fig. 23. Stator electric equation estimator results with $15 \%$ increase for the stator resistor The difference may cause oscillations to the motor speed, and this problem is more important for low speed.

\section{New stator flux estimator for the DTC}

If the motor speed is available, the stator fluxes can be calculated from the flux currents relationships: 


$$
\begin{aligned}
& \Phi_{\mathrm{sd}}=\sigma \mathrm{L}_{\mathrm{s}} \cdot \mathrm{i}_{\mathrm{sd}}+\frac{\mathrm{M}}{\mathrm{L}_{\mathrm{r}}} \cdot \Phi_{\mathrm{rd}} \\
& \Phi_{\mathrm{sq}}=\sigma \mathrm{L}_{\mathrm{s}} \cdot \mathrm{i}_{\mathrm{sq}}+\frac{\mathrm{M}}{\mathrm{L}_{\mathrm{r}}} \cdot \Phi_{\mathrm{rq}}
\end{aligned}
$$

At each sampling period the stator currents are measured and the rotor fluxes are calculated using the rotor electric equations:

$$
\begin{aligned}
& \frac{\mathrm{d} \Phi_{\mathrm{rd}}}{\mathrm{dt}}=-\mathrm{R}_{\mathrm{r}} \cdot \mathrm{i}_{\mathrm{rd}}-\frac{\mathrm{d}(\mathrm{p} \theta)}{\mathrm{dt}} \Phi_{\mathrm{rq}}=-\mathrm{R}_{\mathrm{r}} \cdot\left(\frac{\Phi_{\mathrm{sd}}}{\mathrm{M}}-\frac{\mathrm{L}_{\mathrm{s}}}{\mathrm{M}} \cdot \mathrm{i}_{\mathrm{sd}}\right)-\frac{\mathrm{d}(\mathrm{p} \theta)}{\mathrm{dt}} \Phi_{\mathrm{rq}} \\
& \frac{\mathrm{d} \Phi_{\mathrm{rq}}}{\mathrm{dt}}=-\mathrm{R}_{\mathrm{r}} \cdot \mathrm{i}_{\mathrm{rq}}+\frac{\mathrm{d}(\mathrm{p} \theta)}{\mathrm{dt}} \Phi_{\mathrm{rd}}=-\mathrm{R}_{\mathrm{r}} \cdot\left(\frac{\Phi_{\mathrm{sq}}}{\mathrm{M}}-\frac{\mathrm{L}_{\mathrm{s}}}{\mathrm{M}} \cdot \mathrm{i}_{\mathrm{sq}}\right)+\frac{\mathrm{d}(\mathrm{p} \theta)}{\mathrm{dt}} \Phi_{\mathrm{rd}}
\end{aligned}
$$

The calculation of the stator fluxes using equations (43) and (44) does not require the stator resistor, thus any change in its value has no influence. In fact, the estimator uses the value of the rotor resistor which determines the time constant of the rotor flux. It is obvious that the accuracy in measuring the rotor resistor has no big effect on estimating the stator flux vector using the two previous equations. This is due to the fact that the stator fluxes time constant is smaller than the time constant of the rotor fluxes, as it was shown previously. Fig. 24 shows that for an increase of $15 \%$ in the rotor resistor value, the DTC with the new estimator gives better results.

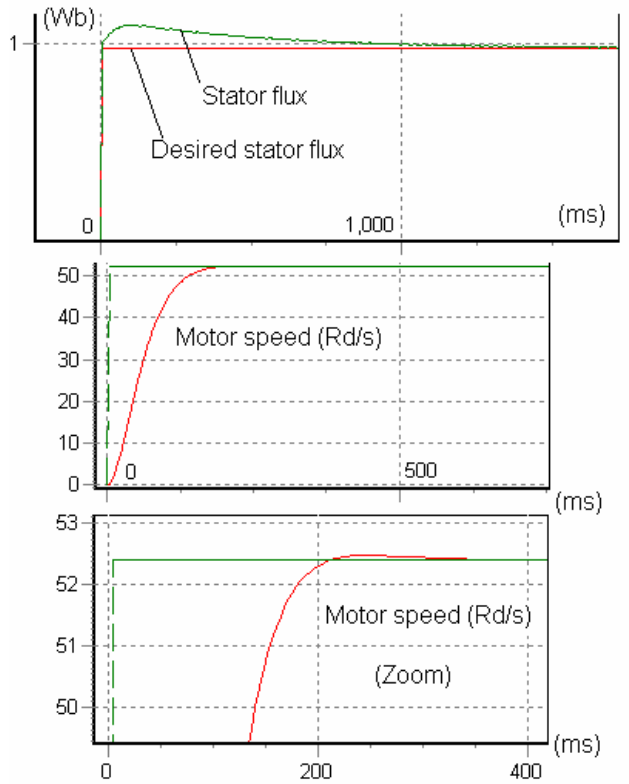

Fig. 24. New estimator results with $15 \%$ increase for the rotor resistor 
The new method of estimating the stator fluxes requires the knowledge of a greater number of motor parameters. It is clear that the new estimator will be more sensitive to the variation of the induction motor saturation level, since it uses the cyclic inductances.

Fig. 25 shows simulation results of the induction motor controlled by the DTC with the new stator fluxes estimator. During the flux weakening phase a big difference between the desired stator flux and the real one was obtained. This influences the dynamic behavior of the speed when applying a load torque of $110(\mathrm{Nm})$ at $3(\mathrm{~s})$.

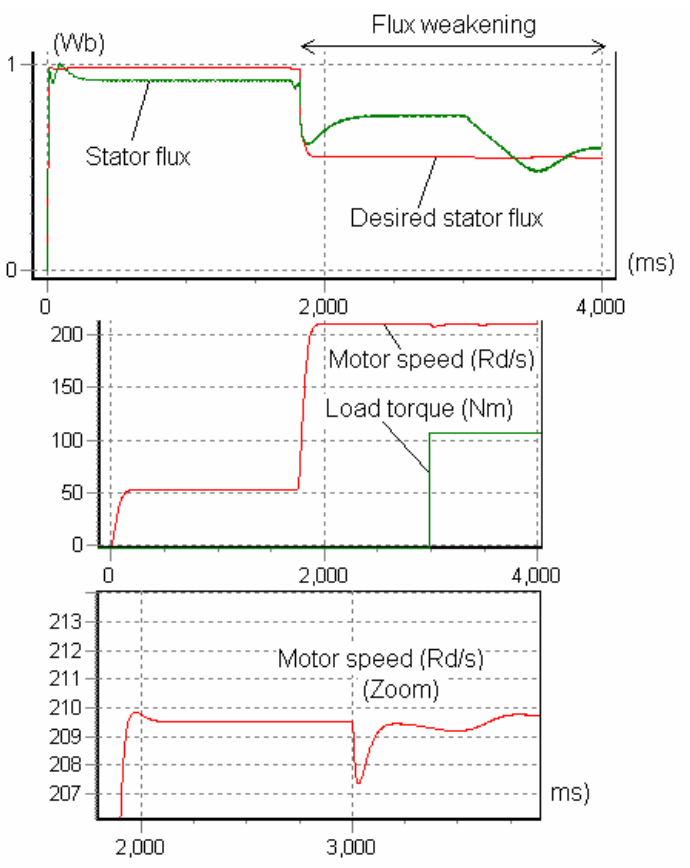

Fig. 25. New estimator sensitivity to the variation of saturation level

It is possible to overcome this problem by tuning the new estimator parameters at each sampling period according to the magnetizing current modulus that can be estimated as described in the section of the saturated FOC.

The scheme of the DTC using this estimator is presented in Fig. 26.

Fig. 27 shows the improvement of dynamic behavior of the induction motor after implementing the adaptive estimator of Fig. 26. 


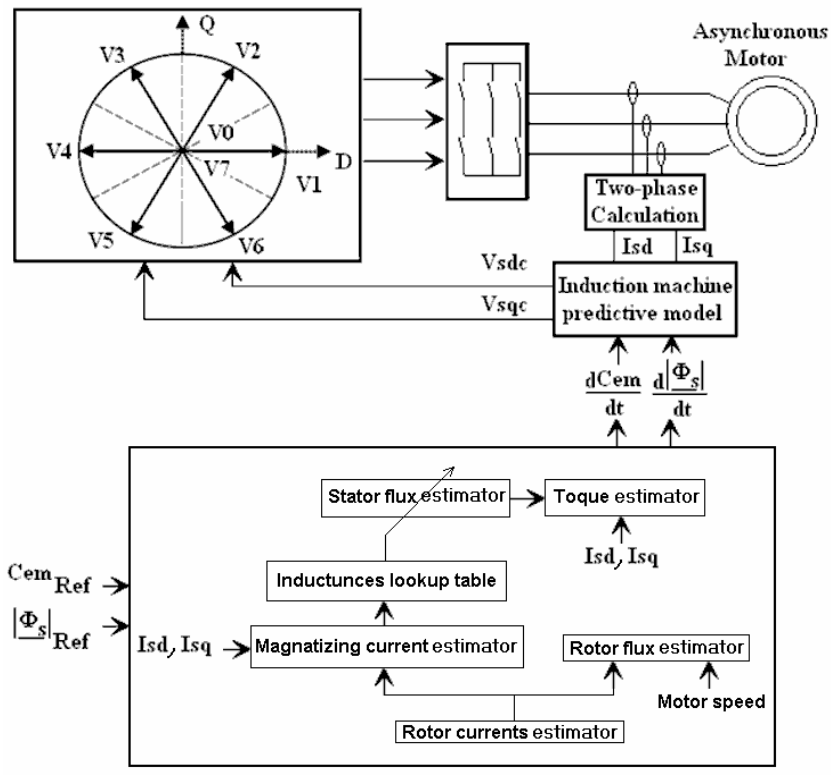

Adaptive stator flux estimator

Fig. 26. Adaptive stator fluxes estimator

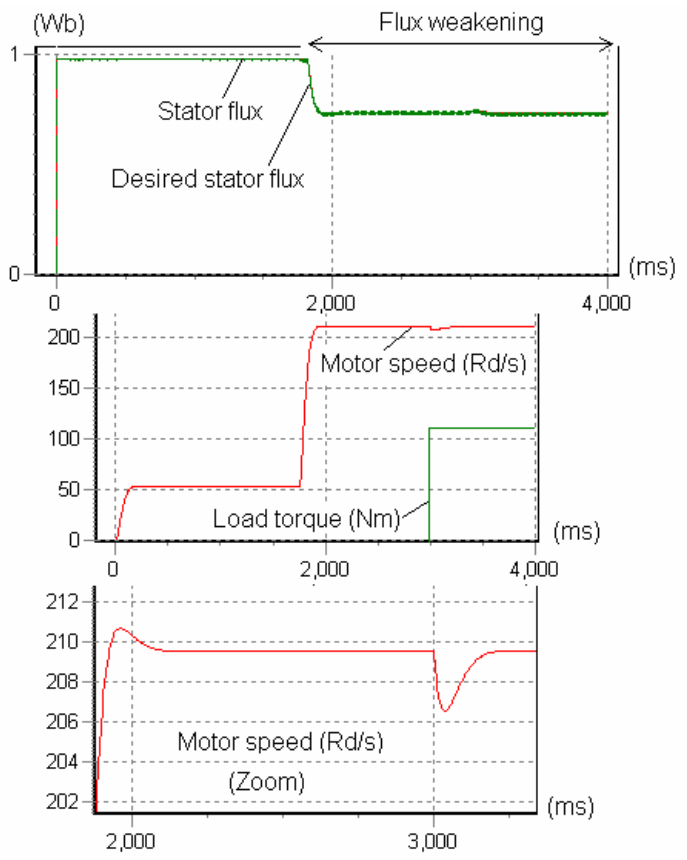

Fig. 27. 45(KW) motor behavior with the adaptive stator flux estimator 
It is possible to combine the two previous estimators. The first one can be used for high speed, while the second estimator can be used for low speed range. In this case, there is no need to program the adaptive estimator of the stator fluxes, since it will not work during the flux weakening phase.

\section{Conclusion}

This chapter has presented a full study of the magnetic state variation of the induction motor. Using a finite elements calculation program, it was possible to establish a two-phase model that takes into account the variation of the saturation level. A very simple resolution method of this new model was presented. The dynamic response of the new model was validated by comparing it to the dynamic response of the induction motor given by the finite element calculation program. After establishing the new model it was possible to review the advanced control laws like the FOC and the DTC laws. A new saturated FOC law was developed in order to enhance the dynamic behavior of the motor during the flux weakening phase, because of the difference between the motor cyclic inductances values and the values of the cyclic inductances introduced in the controllers. Concerning the DTC law, it was shown that a small error in the stator resistor value will highly influence the stator flux estimation, which is done using the stator electric equation. A new stator fluxes estimator was developed using rotor electric equations. This estimator is less sensitive to the motor temperature variation, but it is more sensitive to the variation of the saturation level. An adaptive solution was proposed to tune the estimator parameters according to the saturation level of the motor. Nevertheless the adaptive part added to the DTC algorithm, its computation time remains very small comparing to the FOC algorithm that takes into account the variation of the saturation level. It is important to mention that it is possible to combine the classical estimator and the new estimator according to the speed range. The classical estimator can be used at high speed, but at low speed, it is better to use the new stator flux estimator.

\section{References}

Grotstollen, H. \& Wiesing, J. (1995). Torque capability and control of saturated induction motor over a wide range of flux weakening, Transaction on Industrial Electronics, Vol. 42, No. 4, (August 1990) page numbers (374-381).

Vas, P. \& Alakula, M. (1990). Field oriented control of saturated induction motors, IEEE Transaction on Energy Conversion, Vol. 5, No. 1, (March 1990) page numbers (218224), ISSN 0885-8969.

Kasmieh, T. \& Lefevre, Y. (1998). Establishment of two-phase non-linear simulation model of the dynamic operation of the induction motor, EPJEuropean Physical cburnal, Vol. 1, No. 1, (January 1998) page numbers (57-66).

Vas, P. (1981). Generalized transient analysis of saturated a.c motors, Archiv fur Elektrotechnik, Vol. 64, No. 1-2, (June 1981) page numbers (57-62).

Kasmieh, T. (2008). Adaptive stator flux estimator for the induction motor Direct Torque Control, Proceedings of SPEEDAM 2008, pp. 1239-1241, Ischia, June 2008, Italy. 
Blaschke, F. (1972). The principal of field orientation as applied to the new trans-vector closed-loop control system for rotating field machines, Siemens Review, (May (1972).

Kasmieh, T.( 2002), Presentation of a powerful opened simulator for the saturated induction motor traction system, Proceedings of SPEEDAM 2002, (June 2002), pp. A1 24-A1 37, Ravello, June 2002, Italy.

Noguchi, T. \& Takahashi, I. (1984). Quick torque response control of an induction motor based on a new concept, IEEE Tech, Vol. RM84-76, (September 1984) page numbers (61-70).

Depenbrock, M. \& Steimel A.(1990). High power traction drives and convertors. Proc. of Elect. Drives Symp.'90, pp. 1-9, Capri,1990, Italy.

C.A, Martins.; T.A, Meynard.; X, Roboam. \& A.S, Carvalho2. (1999). A predictive sampling scale model for direct torque control of the induction machine fed by multilevel voltage-source inverters. European Physical eburnal-Applied Physics, AP. 5, (1999) page numbers (51-61). 


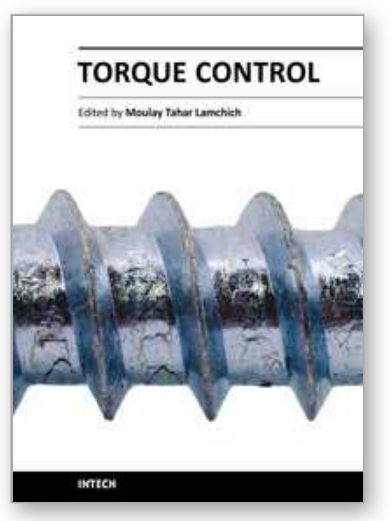

\author{
Torque Control \\ Edited by Prof. Moulay Tahar Lamchich
}

ISBN 978-953-307-428-3

Hard cover, 292 pages

Publisher InTech

Published online 10, February, 2011

Published in print edition February, 2011

This book is the result of inspirations and contributions from many researchers, a collection of 9 works, which are, in majority, focalised around the Direct Torque Control and may be comprised of three sections: different techniques for the control of asynchronous motors and double feed or double star induction machines, oriented approach of recent developments relating to the control of the Permanent Magnet Synchronous Motors, and special controller design and torque control of switched reluctance machine.

\title{
How to reference
}

In order to correctly reference this scholarly work, feel free to copy and paste the following:

Kasmieh Tarek (2011). Induction Machine Vector and Direct Torque Control Improvement during the Flux Weakening Phase, Torque Control, Prof. Moulay Tahar Lamchich (Ed.), ISBN: 978-953-307-428-3, InTech, Available from: http://www.intechopen.com/books/torque-control/induction-machine-vector-and-direct-torquecontrol-improvement-during-the-flux-weakening-phase

\section{INTECH}

open science | open minds

\author{
InTech Europe \\ University Campus STeP Ri \\ Slavka Krautzeka 83/A \\ 51000 Rijeka, Croatia \\ Phone: +385 (51) 770447 \\ Fax: +385 (51) 686166 \\ www.intechopen.com
}

\author{
InTech China \\ Unit 405, Office Block, Hotel Equatorial Shanghai \\ No.65, Yan An Road (West), Shanghai, 200040, China \\ 中国上海市延安西路65号上海国际贵都大饭店办公楼 405 单元 \\ Phone: +86-21-62489820 \\ Fax: +86-21-62489821
}


(C) 2011 The Author(s). Licensee IntechOpen. This chapter is distributed under the terms of the Creative Commons Attribution-NonCommercialShareAlike-3.0 License, which permits use, distribution and reproduction for non-commercial purposes, provided the original is properly cited and derivative works building on this content are distributed under the same license. 